\title{
Stocking and price-reduction decisions for non-instantaneous deteriorating items under time value of money
}

\author{
Freddy Andrés Pérez ${ }^{a^{*}}$, Fidel Torres ${ }^{a}$ and Daniel Mendoza ${ }^{b}$
}

${ }^{a}$ Department of Industrial Engineering, Universidad de los Andes: Cra $1 N^{\circ} 18 \mathrm{~A} 12$, Bogotá, 111711, Colombia

${ }^{b}$ Department of Industrial Engineering. Universidad del Atlántico: Cra $30 N^{\circ} 849$ Puerto Colombia Atlántico, Colombia

\begin{tabular}{l}
\hline C H R O N I C L E \\
\hline Article history: \\
Received January 62018 \\
Received in Revised Format \\
February 182018 \\
Accepted March 242018 \\
Available online \\
March 24 2018 \\
\hline Keywords: \\
Inventory \\
Non-instantaneous deterioration \\
Time value of money \\
Inflation \\
Discounted selling price \\
Shortages
\end{tabular}
\begin{abstract}
A B S T R A C T
Deteriorating inventory models are used as decision support tools for managers primarily, although not exclusively, in the retail trade. The mathematical modeling of deteriorating items allows managers to analyze their inventory management systems to identify areas that can be improved and to measure the corresponding potential benefits. This study develops an enhanced deteriorating inventory model for optimizing the inventory control strategy of companies operating in sectors with deteriorating products. In contrast with previous studies, our model holistically accounts for the overall financial effect of a company's policies on product price discounting and on inventory shortages while considering the time value of money (TVM). We aim to find the optimal replenishment strategy and the optimal price reductions that maximize the discounted profit function of this analytical model over a fixed planning horizon. To this end, we use an economic order quantity model to study the effects of the TVM and inflation. The model accounts for pre- and post-deterioration discounts on the selling price for noninstantaneous deteriorating products with the demand rate being a function of time, pricediscounts and stock-keeping units. Shortages are allowed and partially backordered, depending on the waiting time until the next replenishment. Additionally, we consider the effect of discounts on the selling price when items have either an instant deterioration or a fixed lifetime. We propose five implementable solutions for obtaining the optimal values, and examine their performance. We present some numerical examples to illustrate the applicability of the models, and carry out a sensitivity analysis. The study reveals that accounting for TVM and inventory shortages is complex and time-consuming; nevertheless, we find that accounting for TVM and shortages can be valuable in terms of increasing the yields of companies. Finally, we provide some important managerial implications to support decision-making processes.
\end{abstract}

\section{Introduction}

Most deteriorating inventory models disregard the joint effects of price discounting, the time value of money (TVM), and the inventory policies regarding stockouts (out-of-stock events). However, such issues are important and should not be overlooked. In practice, businesses use methods such as the net present value, the internal rate of return, and the payback period to find a discount strategy that helps them to both meet their sales objectives and obtain the best profit possible for their market demand. For example, in supermarkets, manufacturers and the retailers frequently agree on increasing the shelf space allocation for a product or a product family because large-quantity displays can encourage consumption 
and sales volume (Feng et al., 2017; Koschat, 2008; Mishra et al., 2017). Additionally, because it is undesirable to maintain a high level of unsold products that deteriorate over time (e.g., fruit, vegetables or pharmaceuticals), this common method of increasing demand is generally accompanied by a markdown policy. While a poor discount policy can result in many deteriorated products, a strong discount policy can result in an undesirable level of shortages. Therefore, a joint pricing-inventory model that considers the TVM as well as inventory shortages may be useful to those managers attempting to find an optimal balance between their price discounting strategy and their inventory policy.

Several inventory management studies incorporate the impact of pricing strategies, the existence of shortages, or the effect of TVM into various inventory control models; however, few have considered the holistic effect of these modeling elements. The studies that use inventory models dealing with pricing decisions under the presence of shortages and TVM include: (Chew et al., 2014; C. J. Chung \& Wee, 2008; Dye \& Hsieh, 2011; Dye, Ouyang, et al., 2007; Hou \& Lin, 2006; Krishnan \& Winter, 2010; Li et al., 2008; Pang, 2011; Valliathal \& Uthayakumar, 2011; Wee \& Law, 2001). However, of these studies, only Dye and Hsieh (2011) assume that unsatisfied demand is partially backlogged depending on the length of the customer waiting time. A partial backlog model is more applicable in real life situations than models assuming complete backlogging (Chew et al., 2014; Dye, Ouyang, et al., 2007; Hou \& Lin, 2006; Li et al., 2008; Wee \& Law, 2001), complete lost sales (Krishnan \& Winter, 2010), and even those assuming that a fixed fraction is backordered and the remainder is lost (C. J. Chung \& Wee, 2008; Pang, 2011; Valliathal \& Uthayakumar, 2011).

In addition to the inventory models that consider the joint effect of pricing, shortages, and TVM, many other studies incorporate two of these inventory-modeling characteristics. Such studies develop inventory models that include replenishment and pricing policies for deteriorating items under TVM (e.g., Chew et al., 2009; Dye \& Ouyang, 2011; Jia \& Hu, 2011), and inventory models with deteriorating items addressing a joint pricing and ordering policy under a partial and non-fixed backordering rate (e.g., Abad, 2003; Dye \& Hsieh, 2013; Shavandi et al., 2012; Soni \& Patel, 2012). Other inventory models incorporate both TVM and partial backlogging depending on the waiting time, but do not account for pricing decisions (e.g., Jaggi, Khanna, et al., 2016; Jaggi, Tiwari, et al., 2016; Tiwari et al., 2016; Yang \& Chang, 2013). Notably, no existing pricing-inventory models under TVM and/or shortages incorporate any markdown policies. Hence, there is a need to study and consider price-discount policies to fill this gap in the inventory-pricing control literature.

To best describe the inventory management of several practical situations, we study an inventory model for non-instantaneous deteriorating items and stock-dependent demand under inflationary conditions by using a discounted cash flow approach. We include a partial backlogging rate, the TVM, and a two-phase discount structure in the model. Specifically, we incorporate a demand in which customer consumption is encouraged not only by price reductions but also by large quantity displays of inventory. We assume that the fraction of unsatisfied demand backordered is a decreasing function of the waiting time as that in (e.g., Dye, Hsieh, et al., 2007; Jaggi, Khanna, et al., 2016; Jaggi, Tiwari, et al., 2016; Tiwari et al., 2016; Yang \& Chang, 2013). And we apply the pricing strategy in Panda et al. (2009), in which a price reduction is given before the deterioration of the products can be noted by the consumers, followed by a further discount as soon as the customers start to feel discouraged about buying these deteriorating products.

In contrast to those models disregarding the inflation and TVM (e.g., Feng et al., 2017; Maihami \& Nakhai Kamalabadi, 2012), neglecting shortages (e.g., Mishra et al., 2017; Panda et al., 2009), or assuming instantaneous deterioration (e.g., Bhunia et al., 2013; Dye \& Hsieh, 2011), we respectively release their assumption of constant costs, no shortages, and instantaneous deterioration. As a result, our proposed model is not only suitable when the inflation and TVM can influence the inventory policy variables; it is also a general framework including many previous models as special cases, such as all of the economic order quantity models falling within the broad inventory control literature under stock- 
dependent demand and items deteriorating instantaneously. Many inventory-related studies consider deterioration and stock dependent demand, further details can be found in (Bakker et al., 2012; Goyal \& Giri, 2001; Janssen et al., 2016; Pentico \& Drake, 2011).

As noted by $\mathrm{Wu}$ et al. (2016), it is also worth mentioning that numerous inventory models for deteriorating items under two-warehouse and trade credit compute the interest earned and charged during the credit period but not to the revenue and other costs (e.g., K.-J. Chung \& Cárdenas-Barrón, 2013; K.J. Chung et al., 2014; Jaggi et al., 2017; Shah \& Cárdenas-Barrón, 2015; Teng et al., 2016; Wu et al., 2014). Although we assume that the buyer must pay the procurement cost when products are received, contrary to these models, we apply the discounted cash flow analysis to the revenue and all relevant costs.

Briefly, our contributions are two-fold. First, to the best of our knowledge, this is the first attempt that extends the inventory-pricing literature by considering the two-phase price-discount strategy explained above for non-instantaneous deteriorating items and stock-dependent demand under partial backordering and TVM. Second, we provide, without loss of generality, several multi-dimensional iterative methods to find the optimal policy by taking into account the sufficient condition in which the profit function of a data set is a concave function. Consequently, it is possible to simplify the search for the optimal solution by setting the methods up to find a local maximum. We further simplify the search process by establishing two intuitively good starting values for obtaining the optimal replenishment-discount policy.

The remainder of this paper is organized as follows: Section 2 provides the assumptions and the notations. Section 3 formulates the model and introduces some sub-cases derived from the basic model. The proposed solutions are presented in Section 4, and Section 5 provides some numerical examples to illustrate the applicability of the models. Finally, Section 6 offers some conclusions and remarks.

\section{Notations and assumptions}

\subsection{Notations}

$a \quad$ independent demand parameter, where $a>0$ (unit/time unit)

$\alpha_{1} \quad$ effect of $r_{1}$ discount over demand, where $\alpha_{1}=\left(1-r_{1}\right)^{-n_{1}}$, and $n_{1} \in \mathbb{R}$

$\alpha_{2} \quad$ effect of $r_{2}$ discount over demand, where $\alpha_{2}=\left(1-r_{2}\right)^{-n_{2}}$, and $n_{2} \in \mathbb{R}$

$b \quad$ stock sensitive demand parameter, where $b>0$ (time-unit $\left.{ }^{-1}\right)$

$\beta \quad$ backlogging parameter representing the sensitivity of unsatisfied demand to the waiting time, where $\beta>0$ (time-unit ${ }^{-1}$ )

$c \quad$ purchasing cost per unit (\$/unit)

$C_{o} \quad$ replenishment cost per order (\$/order)

$d \quad$ disposal cost per unit (\$/unit)

$h \quad$ holding cost per unit (\$/unit/time unit)

$H \quad$ time planning horizon (time unit)

$l \quad$ cost of lost sales per unit (\$/unit)

$m$ number of replenishments over $[0, H]$ (a decision variable)

$p \quad$ backorder cost per unit time due to shortages (\$/unit)

$Q_{i} \quad$ ordering quantity per inventory cycle in the $Z_{i}$ model, where $i=1,2,3,4,5,6,7$ (unit)

$r$ net discount rate, representing the TVM (effective per time unit compounded continuously)

$r_{1} \quad$ price-discount per unit, prior to the deterioration period $\left[\tau, T_{1}\right]$ (a decision variable)

$r_{2} \quad$ price-discount offered during the entire deterioration period $\left[\tau, T_{1}\right]$ (a decision variable)

$\mathrm{S} \quad$ selling price per unit (\$/unit)

$t_{1} \quad$ time at which the pre-deterioration discount starts (a decision variable)

$T_{1} \quad$ time at which the inventory level reaches zero (a decision variable)

$T_{B} \quad$ length of the inventory cycle, where $T_{B}=H / m$ (time unit)

$\tau \quad$ time at which deterioration starts 
$\theta$ deterioration rate of the on-hand inventory (over $\left[\tau, T_{1}\right]$ in \%/time unit)

$Z_{1} \quad$ discounted total profit (DTP) for pre- and post-deterioration discount on selling price: a function of $r_{1}, r_{2}, t_{1}, T_{1}$, and $m$

$Z_{2} \quad$ DTP when a markdown is given only during the period in which products exhibit deterioration $\left[\tau, T_{1}\right]$ : a function of $r_{2}, T_{1}$, and $m$

$Z_{3} \quad$ DTP when neither a pre-deterioration nor a post-deterioration discount is offered on the selling price: a function of $T_{1}$ and $m$

$Z_{4} \quad$ DTP when products deteriorate instantaneously and a markdown is held during the entire inventory cycle: a function of $r_{2}, T_{1}$, and $m$

$Z_{5} \quad$ DTP when products deteriorate instantaneously and no discount is offered: a function of $T_{1}$, and $m$

$Z_{6} \quad$ DTP when items have a fixed shelf life and a markdown is given prior to the expiration of the onhand inventory: a function of $r_{1}, t_{1}, T_{1}$, and $m$.

$Z_{7} \quad$ DTP when products have a fixed life time and no pre-deterioration discount is given: a function of $T_{1}$ and $m$.

\subsection{Assumptions}

We make the following assumptions in developing the inventory-pricing inventory model:

- The system operates for a finite planning horizon $H$.

- The replenishment rate is infinite and the lead time is zero.

- A single non-instantaneously deteriorating item is assumed. During the fixed period, $\tau$, the on-hand inventory does not exhibit deterioration, and after that time the inventory deteriorates at a constant rate $\theta$, where $0<\theta<1$. There is no replacement or repair of the deteriorated units during the entire planning horizon.

- The demand rate function $D\left(r_{1}, r_{2}, t\right)$ is deterministic. It is a function of the instantaneous stock level $I(t)$, the pre- and post-deterioration discount on the selling price $r_{1}, r_{2}$, and the waiting time $T_{B}-t$. We assume that the demand function $D\left(r_{1}, r_{2}, \mathrm{t}\right)$ is given as

$$
D\left(\mathrm{r}_{1}, \mathrm{r}_{2}, \mathrm{t}\right)= \begin{cases}a-b I(t), & \text { if } 0 \leq t \leq t_{1} \\ \alpha_{1}(a+b I(t)), & \text { if } t_{1} \leq t \leq \tau \\ \alpha_{2} a, & \text { if } \tau \leq t \leq T_{1} \\ \mathrm{a} e^{-\beta\left(T_{B}-t\right)}, & \text { if } T_{1} \leq t \leq T_{B}\end{cases}
$$

- Shortages are allowed and partially backlogged. The fraction of the shortages backordered is $e^{-\beta\left(T_{B}-t\right)}$, where $T_{B}-t$ is the waiting time until the next replenishment and $\beta$ is a non-negative parameter. Note that $e^{-\beta\left(T_{B}-t\right)}$ is a decreasing function of the waiting time, and that it represents situations in which a longer waiting time results in a greater amount of lost sales.

\section{Problem formulation}

This paper examines the effect of TVM and inflation in a deterministic inventory model with pre- and post-deterioration discounts on the selling price for non-instantaneous deterioration items. The objective is to maximize the DTP over a finite horizon $H$. Accordingly, the total time horizon $H$ is divided into $m$ equal parts of length $T_{B}$ (i.e., $T_{B}=H / m$ ). At the beginning of the replenishment cycle, the inventory level increases to $Q_{1}$. As time progresses, the inventory level decreases up to time $\tau$ under the influence of the stock dependency of demand and the pre-deterioration mark-down policy. After $\tau$, deterioration starts, and the inventory level decreases because of stock deterioration and constant demand until it reaches zero level at $T_{1}$. Ultimately, backorders are accumulated from time $T_{1}$ to $T_{B}$, and the same 
described process is repeated during the entire time horizon $H$. This inventory cycle is graphically represented in Fig. 1.

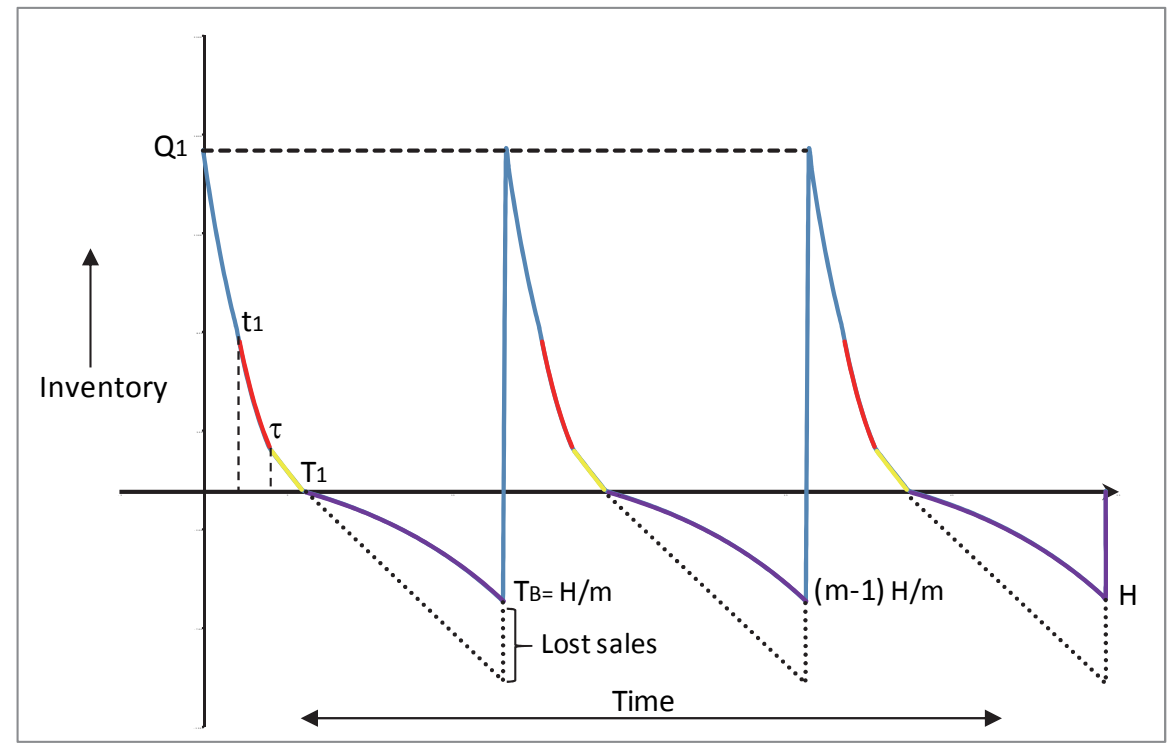

Fig. 1 Inventory system cycle $(\mathrm{m}=3)$

During the time interval $\left[0, T_{B}\right]$, the differential equations representing the evolution of the on-hand inventory are given by

$\frac{d I(t)}{d t}=-a-b I(t), \quad$ if $0 \leq t \leq t_{1}$,

$\frac{d I(t)}{d t}=-\alpha_{1}(a+b I(t)), \quad$ if $t_{1} \leq t \leq \tau$,

$\frac{d I(t)}{d t}=-\alpha_{2} a-\theta I(t), \quad$ if $\tau \leq t \leq T_{1}$,

$\frac{d I(t)}{d t}=-e^{-\beta\left(T_{B}-t\right)} a, \quad$ if $T_{1} \leq t \leq T_{B}$.

With the initial and boundary conditions $I(0)=Q_{1}$ and $I\left(T_{1}\right)=0$, solving the above equations yields

$$
\begin{array}{llrl}
I(t) & =\frac{a}{b}\left(e^{-b t}-1\right)+Q_{1} e^{-b t}, & & \text { if } 0 \leq t \leq t_{1}, \\
I(t) & =\frac{a}{b}\left(e^{\alpha_{1} b\left(t_{1}-t\right)-b t_{1}}-1\right)+Q_{1} e^{\alpha_{1} b\left(t_{1}-t\right)-b t_{1},}, & & \text { if } t_{1} \leq t \leq \tau, \\
I(t) & =\frac{a \alpha_{2}}{\theta}\left[e^{\theta\left(T_{1}-t\right)}-1\right], & & \text { if } \tau \leq t \leq T_{1} \\
I(t) & =\frac{a}{\beta} e^{-\beta\left(T_{B}-t\right)}\left[e^{-\beta\left(t-T_{1}\right)}-1\right], & & \text { if } T_{1} \leq t \leq T_{B} .
\end{array}
$$

If we put $t=\tau$ into Eq. (6) and Eq. (7), the ordering quantity per inventory cycle is obtained as follows

$$
Q_{1}=\left(\frac{a \alpha_{2}}{\theta}\left(e^{\theta\left(T_{1}-\tau\right)}-1\right)+\frac{a}{b}\right) e^{\alpha_{1} b\left(\tau-t_{1}\right)+b t_{1}}-\frac{a}{b} .
$$

Based on these equations, we can obtain the DTP by deriving the present values of the holding cost (HC), disposal cost (DC), shortage cost (SC), cost of lost sales (LC), ordering cost (RC), purchase cost (PC), and sales revenue (SR) as follows. 
From Eq. (5), Eq. (6), and Eq. (7), the present value of the total holding and disposal costs during the entire horizon $H$ is

$$
\begin{aligned}
& H C+D C=\sum_{j=1}^{m}\left[h \int_{0}^{t_{1}} e^{-r t} I(t) d t+h \int_{t_{1}}^{\tau} e^{-r t} I(t) d t+(h+\right. \\
& \left.\theta d) \int_{\tau}^{T_{1}} e^{-r t} I(t) d t\right] e^{-(j-1) r T_{B}} .
\end{aligned}
$$

From Eq. (8), the present value of the total backorder cost because of shortages during the entire time horizon $H$ is

$$
\begin{aligned}
& S C=\sum_{j=1}^{m}\left[-p \int_{T_{1}}^{T_{B}} e^{-r t} I(t) d t\right] e^{-j r T_{B}}=\frac{-p a}{\beta(\beta-r)}\left[e^{-r T_{1}-\beta\left(\frac{H}{m}-T_{1}\right)}\left(1+\frac{\beta-r}{r}\right)-\right. \\
& \left.e^{-\frac{r H}{m}}\left[1+\frac{\beta-r}{r} e^{-\beta\left(\frac{H}{m}-T_{1}\right)}\right]\right] \frac{1-e^{-r H}}{e^{\frac{r H}{m}}-1} .
\end{aligned}
$$

Again, from Eq. (8), the present value of the cost of lost sales is

$$
\begin{aligned}
& L C=\sum_{j=1}^{m}\left[l a \int_{T_{1}}^{T_{B}} e^{-r t}\left[1-e^{-\beta\left(T_{B}-t\right)}\right] d t\right] e^{-j r T_{B}}=\frac{l a}{r}\left[e^{-r T_{1}}\left(1+\frac{r}{\beta-r} e^{-\beta\left(H / m-T_{1}\right)}\right)-\right. \\
& \left.e^{-r H / m}\left(1+\frac{r}{\beta-r}\right)\right] \frac{1-e^{-r H}}{e^{\frac{r H}{m}}-1}
\end{aligned}
$$

From Eq. (9), and taking into account that shortages during the first inventory cycle should be backordered at the beginning of the next cycle, and that shortages during the last cycle are replenished at time $m * T_{B}=H$, the present value of the purchase cost is

$$
\begin{aligned}
& P C=c\left\{\sum_{j=1}^{m} Q_{1} e^{-(j-1) r T_{B}}+\sum_{j=1}^{m}\left[-I\left(T_{B}\right)\right] e^{-j r T_{B}}\right\}=c\left[Q_{1} \frac{1-e^{-r H}}{1-e^{-\frac{r H}{m}}}+\frac{a}{\beta}(1-\right. \\
& \left.\left.e^{-\beta\left(\frac{H}{m}-T_{1}\right)}\right) \frac{1-e^{-r H}}{e^{\frac{r H}{m}}-1}\right] .
\end{aligned}
$$

Now, because there are $m+1$ replenishments in the entire time horizon $H$, the present value of the fixed cost per order (setup cost) is given by

$$
R C=\sum_{j=0}^{m} C_{0} e^{-j r T_{B}}=C_{0} \frac{e^{r H / m}-e^{-r H}}{e^{r H / m}-1},
$$

and the present value of the sales revenue in the entire horizon $H$ is given as

$$
\begin{aligned}
& S R=S\left[\int_{0}^{t_{1}} e^{-r t}(a+b I(t)) d t+\alpha_{1}\left(1-r_{1}\right) \int_{t_{1}}^{\tau} e^{-r t}(a+b I(t)) d t+\alpha_{2}(1-\right. \\
& \left.\left.r_{2}\right) \int_{\tau}^{T_{1}} e^{-r t} a d t-I\left(T_{B}\right)\right] \frac{1-e^{-r H}}{e^{\frac{r H}{m}}-1}
\end{aligned}
$$

Thus, the discounted total profit (DTP) of the inventory system during the planning horizon $H$ is

$$
\begin{aligned}
& Z_{1}=S R-P C-H C-D C-R C-L C-S C=s \frac{a}{r}\left[e^{-r t_{1}}\left(\gamma_{1}-1\right)+e^{-r \tau}\left(\gamma_{2}-\gamma_{1}\right)+\right. \\
& \left.\left(1-\gamma_{2} e^{-r T_{1}}\right)\right] \frac{1-e^{-r H}}{e^{\frac{r H}{m}}-1}+\left(s b \frac{1-e^{-r H}}{e^{\frac{r H}{m}}-1}-h \frac{1-e^{-r H}}{1-e^{-\frac{r H}{m}}}\right) \int_{0}^{t_{1}} e^{-r t} I(t) d t+\left(s \gamma_{1} b \frac{1-e^{-r H}}{e^{\frac{r H}{m}}-1}-\right.
\end{aligned}
$$


$\left.h \frac{1-e^{-r H}}{1-e^{-\frac{r H}{m}}}\right) \int_{t_{1}}^{\tau} e^{-r t} I(t) d t-(h+\theta d) \frac{1-e^{-r H}}{1-e^{-r \frac{H}{m}}} \int_{\tau}^{T_{1}} e^{-r t} I(t) d t-P C-L C-S C-$
$C_{0} \frac{e^{r \frac{H}{m}}-e^{-r H}}{e^{r \frac{H}{m}}-1}+\frac{s a}{\beta}\left(1-e^{-\beta\left(\frac{H}{m}-T_{1}\right)}\right) \frac{1-e^{-r H}}{e^{\frac{r H}{m}}-1}$

where

$\gamma_{1}=\left(1-r_{1}\right) /\left(1-r_{1}\right)^{n 1}, \gamma_{2}=\left(1-r_{2}\right) /\left(1-r_{2}\right)^{n 2}$,

$\int_{0}^{t_{1}} e^{-r t} I(t) d t=\left(\frac{a}{b}+Q_{1}\right)\left(\frac{1}{r+b}\right)\left(1-e^{-t_{1}(r+b)}\right)+\frac{a}{b r}\left(e^{-r t_{1}}-1\right)$,

$\int_{t_{1}}^{\tau} e^{-r t} I(t) d t=\left(\frac{a}{b}+Q_{1}\right) \frac{1}{r+\alpha_{1} b}\left(e^{-t_{1}(r+b)}-e^{-r \tau+\alpha_{1} b\left(t_{1}-\tau\right)-b t_{1}}\right)+\frac{a}{b r}\left(e^{-r \tau}-e^{-r t_{1}}\right)$,

$\int_{\tau}^{T_{1}} e^{-r t} I(t) d t=\frac{a \alpha_{2}}{r \theta}\left[e^{-r \tau}\left(\frac{r e^{\theta\left(T_{1}-\tau\right)}}{r+\theta}-1\right)-e^{-r T_{1}}\left(\frac{r}{r+\theta}-1\right)\right]$.

Here, the problem is to determine the optimal values of $r_{1}, r_{2}, t_{1}, T_{1} \geq 0$ and $m \in Z^{+}$so that $Z_{1}$ is maximized, but considering the constraint in which the pre- and post-deterioration discounts on the selling price are given in such a way that the discounted selling price is not less than the unit cost of products. Hence, it is a five-issue decision-making problem for a retailer that can be expressed as

$$
\begin{array}{ll}
\max & Z_{1}\left(r_{1}, r_{2}, t_{1}, T_{1}, m\right) \\
\text { subject to } & r_{1}<1-c / S \\
& r_{2}<1-c / S \\
& t_{1} \leq \tau \leq T_{1} \leq H / m \\
& r_{1}, r_{2}, t_{1}, T_{1} \geq 0, m \in Z^{+} .
\end{array}
$$

\section{Special cases}

Based on the results obtained in Section 3 for $Z_{1}$, we can easily derive six additional models that arise from relaxing the assumptions on the discounted selling price offered to customers and the type of deterioration that the inventory system deals with. Thus, this section provides the inventory models representing the following scenarios:

- A discount on the selling price is given only as soon as deterioration starts $\left(Z_{2}\right)$.

- There is neither a pre-deterioration nor a post-deterioration discount on the selling price $\left(Z_{3}\right)$.

- Products deteriorate instantaneously and a markdown is held during the entire inventory cycle $\left(Z_{4}\right)$.

- Products deteriorate instantaneously, and no discount is offered $\left(Z_{5}\right)$.

- Items in stock have a known fixed shelf life, and a markdown is given prior to the expiration of the on-hand inventory $\left(Z_{6}\right)$.

- Products have fixed lifetime, and there is no pre-deterioration discount $\left(Z_{7}\right)$.

4.1 Model $Z_{2}$ : only a post-deterioration discount on the unit selling price $\left(t_{1}=\tau, r_{1}=0\right)$

In this scenario, a markdown is only allowed during the deterioration period $\left[\tau, T_{1}\right]$; hence, we set the pre-deterioration discount $r_{1}$ at zero and let $t_{1}$ be equal to $\tau$. Correspondingly, equation (9) becomes:

$$
Q_{2}=\left(\frac{a \alpha_{2}}{\theta}\left(e^{\theta\left(T_{1}-\tau\right)}-1\right)+\frac{a}{b}\right) e^{b \tau}-\frac{a}{b},
$$

and Eq. (16) becomes: 


$$
\begin{gathered}
Z_{2}=s \frac{a}{r}\left[\left(1-e^{-r \tau}\right)+\frac{\left(1-r_{2}\right)}{\left(1-r_{2}\right)^{n 2}}\left(e^{-r \tau}-e^{-r T_{1}}\right)\right] \frac{1-e^{-r H}}{e^{\frac{r H}{m}}-1}-P C-L C-S C+\left(s b \frac{1-e^{-r H}}{e^{\frac{r H}{m}}-1}-\right. \\
\left.\quad h \frac{1-e^{-r H}}{1-e^{-\frac{r H}{m}}}\right)\left[\left(\frac{a}{b}+Q_{2}\right)\left(\frac{1}{r+b}\right)\left(1-e^{-\tau(r+b)}\right)+\frac{a}{b r}\left(e^{-r \tau}-1\right)\right]-C_{0} \frac{e^{\frac{r H}{m}}-e^{-r H}}{e^{\frac{r H}{m}}-1}+\frac{s a}{\beta}(1- \\
\left.e^{-\beta\left(\frac{H}{m}-T_{1}\right)}\right) \frac{1-e^{-r H}}{e^{\frac{r H}{m}}-1}-(h+\theta d)\left(\frac{1-e^{-r H}}{1-e^{-\frac{r H}{m}}}\right) \frac{a \alpha_{2}}{r \theta}\left[e^{-r \tau}\left(\frac{r e^{\theta\left(T_{1}-\tau\right)}}{r+\theta}-1\right)-e^{-r T_{1}}\left(\frac{r}{r+\theta}-1\right)\right],
\end{gathered}
$$

where SC and LC are given by Eq. (11) and Eq. (12) respectively, and PC is found by substituting (17) for $Q_{1}$ into Eq. (13).

Therefore, this optimization problem can be described as

$\max Z_{2}\left(r_{2}, T_{1}, m\right)$

subject to $\quad r_{2}<1-c / S$

$$
\begin{aligned}
& \tau \leq T_{1} \leq H / m \\
& r_{2}, T_{1} \geq 0, m \in Z^{+} .
\end{aligned}
$$

\subsection{Model $Z_{3}$ : no discount on unit selling price $\left(t_{1}=\tau, r_{1}=r_{2}=0\right)$}

In this scenario, a conservative strategy is pursued where no discounts are offered on the inventories at any time. Correspondingly, by substituting, $r_{1}=r_{2}=0$ and $t_{1}=\tau$ into equations (9) and (16), we respectively get

$$
Q_{3}=\left(\frac{a}{\theta}\left(e^{\theta\left(T_{1}-\tau\right)}-1\right)+\frac{a}{b}\right) e^{b \tau}-\frac{a}{b}
$$

and

$$
\begin{aligned}
& Z_{3}=s \frac{a}{r}\left[\left(1-e^{-r \tau}\right)+\left(e^{-r \tau}-e^{-r T_{1}}\right)\right] \frac{1-e^{-r H}}{e^{\frac{r H}{m}}-1}-P C-L C-S C-C_{0} \frac{e^{\frac{r H}{m}}-e^{-r H}}{e^{\frac{r H}{m}}-1}+ \\
& \left(s b \frac{1-e^{-r H}}{e^{\frac{r H}{m}}-1}-h \frac{1-e^{-r H}}{1-e^{-\frac{r H}{m}}}\right)\left[\left(\frac{a}{b}+Q_{3}\right)\left(\frac{1}{r+b}\right)\left(1-e^{-\tau(r+b)}\right)+\frac{a}{b r}\left(e^{-r \tau}-1\right)\right]-(h+ \\
& \theta d)\left(\frac{1-e^{-r H}}{1-e^{-\frac{r H}{m}}}\right) \frac{a}{r \theta}\left[e^{-r \tau}\left(\frac{r e^{\theta\left(T_{1}-\tau\right)}}{r+\theta}-1\right)-e^{-r T_{1}}\left(\frac{r}{r+\theta}-1\right)\right]+\frac{s a}{\beta}\left(1-e^{-\beta\left(\frac{H}{m}-T_{1}\right)}\right) \frac{1-e^{-r H}}{e^{\frac{r H}{m}}-1},
\end{aligned}
$$

where PC can be obtained by substituting Eq. (19) for $Q_{1}$ in Eq. (13), and SC and LC are given by Eq. (11) and Eq. (12), respectively.

Therefore, this maximization problem can be described as

$\max Z_{3}\left(T_{1}, m\right)$

$$
\begin{aligned}
& 0<T_{1} \leq H / m \\
& T_{1} \geq 0, m \in Z^{+} .
\end{aligned}
$$

4.3.Model $Z_{4}$ : instant deterioration with a post deterioration discount $\left(\tau=t_{1}=r_{1}=0\right)$

When a product deteriorates as soon as it is received in stock, some companies may adopt a strategy of always maintaining a lower price than their competitors maintain. Here, the products may have a known 
price in the industry, and a lower price may be given in the form of discount over the market price. Hence, by setting $\tau, t_{1}$, and $r_{1}$ at zero in (9) and (16), we get the order quantity as

$Q_{4}=\frac{a \alpha_{2}}{\theta}\left(e^{\theta T_{1}}-1\right)$

and the DTP as

$$
\begin{aligned}
& Z_{4}=s \frac{a}{r}\left[\frac{\left(1-r_{2}\right)}{\left(1-r_{2}\right)^{n 2}}\left(1-e^{-r T_{1}}\right)\right] \frac{1-e^{-r H}}{e^{\frac{r H}{m}}-1}-P C-L C-S C-C_{0} \frac{e^{\frac{r H}{m}}-e^{-r H}}{e^{\frac{r H}{m}}-1}-(h+ \\
& \left.\theta d)\left(\frac{1-e^{-r H}}{1-e^{-\frac{r H}{m}}}\right) \frac{a \alpha_{2}}{r \theta}\left[\left(\frac{r e^{\theta T_{1}}}{r+\theta}-1\right)-e^{-r T_{1}}\left(\frac{r}{r+\theta}-1\right)\right]+\frac{s a}{\beta}\left(1-e^{-\beta\left(\frac{H}{m}-T_{1}\right.}\right)\right) \frac{1-e^{-r H}}{e^{\frac{r H}{m}}-1}
\end{aligned}
$$

where SC and LC are equal to Eq. (11) and Eq. (12), and PC is equal to Eq. (13) when replacing $Q_{4}$ for $Q_{1}$.

Therefore, this maximization problem can be described as

$$
\begin{aligned}
\max \quad Z_{4}\left(r_{2},\right. & \left.T_{1}, m\right) \\
& r_{2}<1-c / S \\
& 0<T_{1} \leq H / m \\
& r_{2}, T_{1} \geq 0, m \in Z^{+} .
\end{aligned}
$$

4.4.Model $Z_{5}$ : instant deterioration and without discount $\left(\tau=t_{1}=0, r_{1}=r_{2}=0\right)$

In this scenario, products deteriorate instantaneously and no price discounts are allowed. Given that $\tau=$ $t_{1}=r_{1}=r_{2}=0$, equation (21) becomes

$$
Q_{5}=\frac{a}{\theta}\left(e^{\theta T_{1}}-1\right)
$$

and Eq. (22) becomes

$$
\begin{aligned}
& Z_{5}=s \frac{a}{r}\left(1-e^{-r T_{1}}\right) \frac{1-e^{-r H}}{e^{\frac{r H}{m}}-1}-P C-L C-S C-C_{0} \frac{e^{r H / m}-e^{-r H}}{e^{r H / m}-1}-(h+ \\
& \left.\theta d)\left(\frac{1-e^{-r H}}{1-e^{-\frac{r H}{m}}}\right) \frac{a}{r \theta}\left[\left(\frac{r e^{\theta T_{1}}}{r+\theta}-1\right)-e^{-r T_{1}}\left(\frac{r}{r+\theta}-1\right)\right]+\frac{s a}{\beta}\left(1-e^{-\beta\left(\frac{H}{m}-T_{1}\right.}\right)\right) \frac{1-e^{-r H}}{e^{\frac{r H}{m}}-1}
\end{aligned}
$$

where LC and SC are equal to Eq. (11) and EQ. (12), and PC is equal to Eq. (13) when using $Q_{5}$ instead of $Q_{1}$.

Therefore, this maximization problem can be described as

$\begin{array}{ll}\max & Z_{5}\left(T_{1}, m\right) \\ \text { Subject to } & 0<T_{1} \leq H / m \\ & T_{1} \geq 0, m \in Z^{+} .\end{array}$

4.5.Model $Z_{6}$ : fixed life time products with pre deterioration discount $\left(\tau \rightarrow T_{1}, r_{2}=0\right)$

In this scenario, there is a pre-deterioration discount on the selling price, and the time $T_{1}$ at which the inventory level reaches zero is assumed to be less than the life time of the items. Thus, the order quantity (25) and DTP (26) can be found from equations (9) and (16) by letting $\tau \rightarrow T_{1}$ and $r_{2}=0$ as follows 
$Q_{6}=\frac{a}{b}\left(e^{\alpha_{1} b\left(T_{1}-t_{1}\right)+b t_{1}}-1\right)$,

and

$$
\begin{aligned}
& Z_{6}=s \frac{a}{r}\left[e^{-r t_{1}}\left(\frac{\left(1-r_{1}\right)}{\left(1-r_{1}\right)^{n 1}}-1\right)+\left(1-\frac{\left(1-r_{1}\right)}{\left(1-r_{1}\right)^{n 2}} e^{-r T_{1}}\right)\right] \frac{1-e^{-r H}}{e^{\frac{r H}{m}}-1}+\left(s b \frac{1-e^{-r H}}{e^{\frac{r H}{m}}-1}-\right. \\
& \left.h \frac{1-e^{-r H}}{1-e^{-\frac{r H}{m}}}\right)\left[\left(\frac{a}{b}+Q_{6}\right)\left(\frac{1}{r+b}\right)\left(1-e^{-t_{1}(r+b)}\right)+\frac{a}{b r}\left(e^{-r t_{1}}-1\right)\right]+\left(s \alpha_{1}\left(1-r_{1}\right) b \frac{1-e^{-r H}}{e^{\frac{r H}{m}}-1}-\right. \\
& \left.h \frac{1-e^{-r H}}{1-e^{-\frac{r H}{m}}}\right)\left[\left(\frac{a}{b}+Q_{6}\right) \frac{1}{r+\alpha_{1} b}\left(e^{-t_{1}(r+b)}-e^{-r T_{1}+\alpha_{1} b\left(t_{1}-T_{1}\right)-b t_{1}}\right)+\frac{a}{b r}\left(e^{-r T_{1}}-e^{-r t_{1}}\right)\right]-P C- \\
& \left.L C-S C-C_{0} \frac{e^{\frac{r H}{m}}-e^{-r H}}{e^{\frac{r H}{m}}-1}+\frac{s a}{\beta}\left(1-e^{-\beta\left(\frac{H}{m}-T_{1}\right.}\right)\right) \frac{1-e^{-r H}}{e^{\frac{r H}{m}}-1},
\end{aligned}
$$

where PC can be obtained when applying Eq. (13) with $Q_{1}$ replaced by Eq. (25), and LC and PC can be calculated from Eq. (11) and Eq. (12), respectively.

Therefore, this maximization problem can be described as

$$
\begin{array}{cl}
\max & Z_{6}\left(r_{1}, \mathrm{t}_{1}, T_{1}, m\right) \\
& r_{1}<1-c / S \\
& t_{1} \leq T_{1} \leq \tau<H / m \\
& r_{1}, t_{1}, T_{1} \geq 0, m \in Z^{+} .
\end{array}
$$

4.6.Model $Z_{7}$ : fixed life time products with no discount $\left(\tau, t_{1} \rightarrow T_{1}\right.$ and $\left.r_{1}=r_{2}=0\right)$

Substituting the expressions $t_{1}=T_{1}$ and $r_{1}=0$ into Eq. (25) and Eq. (26), we get the order quantity as

$$
Q_{7}=\frac{a}{b}\left(e^{b T_{1}}-1\right)
$$

and the DTP as

$$
\begin{aligned}
& Z_{7}=s \frac{a}{r}\left(1-e^{-r T_{1}}\right) \frac{1-e^{-r H}}{e^{\frac{r H}{m}}-1}+\frac{s a}{\beta}\left(1-e^{-\beta\left(\frac{H}{m}-T_{1}\right)}\right) \frac{1-e^{-r H}}{e^{\frac{r H}{m}}-1}-P C-C_{0} \frac{e^{\frac{r H}{m}}-e^{-r H}}{e^{\frac{r H}{m}}-1}+ \\
& \left(s b \frac{1-e^{-r H}}{e^{\frac{r H}{m}}-1}-h \frac{1-e^{-r H}}{1-e^{-\frac{r H}{m}}}\right)\left[\left(\frac{a}{b}+Q_{7}\right)\left(\frac{1}{r+b}\right)\left(1-e^{-T_{1}(r+b)}\right)+\frac{a}{b r}\left(e^{-r T_{1}}-1\right)\right]-L C-S C,
\end{aligned}
$$

where SC and LC are respectively provided by Eq. (11) and Eq. (12), and PC is given by Eq. (13) when $Q_{1}$ is replaced by (27).

Therefore, this maximization problem can be described as

$$
\begin{array}{ll}
\max & Z_{7}\left(T_{1}, m\right) \\
\text { subject to } & 0<T_{1} \leq \tau \leq H / m \\
& T_{1} \geq 0, m \in Z^{+} .
\end{array}
$$




\section{Solution procedures}

It is difficult to obtain the optimal values of the models described in Section 4. The simplest first derivative form of $Z_{1}$ in Eq. (16) with respect to $T_{1}$, when solving for a single set of parameters under $r_{1}=r_{2}=t_{1}=0$ and any known $m$, is given as $\pm A e^{\theta T_{1}}-B e^{\beta T_{1}}+C e^{(\beta-r) T_{1}}+D e^{-r T_{1}}$, where $A, B, C$, and $D$ belong to the set of all real numbers. This method of obtaining the stationary points of our functions is not analytically feasible. Thus, despite this difficulty, we adapt and code five nonderivative multidimensional search methods (Bazaraa et al., 2006) to make them adequate in dealing with all of the constrained mixed-integer nonlinear programming problems referred to in Section 4 . The solution procedures follow.

\subsection{Solution I: cyclic coordinate method (C-method)}

Step 1. Assign to each of the $n$ continuous decision variables $x_{1}, \ldots x_{n}$, a minimum $a$ and a maximum $b$ allowable value (i.e., $\left.a_{1} \leq x_{1} \leq b_{1}, \ldots, a_{n} \leq x_{n} \leq b_{n}\right)$. Let best be equal to a large negative number $(-M)$. Select a plausible range of values for $m$ ( $m$ Min $\leq m \leq m M a x)$. Let $m=m$ Min, choose a scalar $\varepsilon>0$ to be used for terminating the search with each $m$, and go to Step 2 .

Step 2. If $m>\max$, then stop. Otherwise, let $\mathbf{D}$ be a unit matrix with row vectors $\mathbf{d}_{1}, \ldots, \mathbf{d}_{\mathrm{n}}$ as coordinate directions. Choose an initial point $\mathbf{x}_{1}=\left(x_{1}, \ldots, x_{n}\right)$, let $\mathbf{y}_{1}=\mathbf{x}_{1}=\left(y_{1}, \ldots, y_{n}\right)$, let $k=j=1$, and go to Step 3.

Step 3. Let $\lambda_{j}$ be an optimal solution to the problem to maximize $f\left(\mathbf{y}_{j}+\lambda \mathbf{d}_{j}\right)$ subject to $a_{j} \leq y_{j}+\lambda \leq$ $b_{j}$, and let $\mathbf{y}_{j+1}=\mathbf{y}_{j}+\lambda \mathbf{d}_{j}$. If $j<n$, then replace $j$ by $j+1$, and repeat Step 3. If $j=n$, then let $\mathbf{x}_{k+1}=$ $\mathbf{y}_{n+1}$. If $\left\|\mathbf{x}_{k+1}-\mathbf{x}_{k}\right\|<\varepsilon$, and then go to Step 5. Otherwise, go to Step 4.

Step 4. Let $\mathbf{y}_{1}=\mathbf{x}_{k+1}$, let $j=1$, replace $k$ by $k+1$, and repeat Step 3 .

Step 5. Let best $t_{m}=f\left(\mathbf{x}_{k+1}\right)$ and Sol $_{m}=\mathbf{x}_{k+1}$. If best $<$ best $_{m}$, then replace best by best $t_{m}$ and bestSol by Sol $_{m}$. Replace $m$ by $m+1$, and go to Step 2 .

\subsection{Solution II: Hooke and Jeeves's method using line search (HL-method)}

Steps 1, 2, and 3. Follow Steps 1, 2, and 3 from Solution I.

Step 4. Let $\mathbf{d}=\mathbf{x}_{k+1}-\mathbf{x}_{k}$, and let $\hat{\lambda}$ be an optimal solution to the problem to maximize $f\left(\mathbf{y}_{j}+\lambda \mathbf{d}_{j}\right)$ subject to $\min \left[u_{i}\right]_{i=1}^{n} \leq \lambda \leq \max \left[v_{i}\right]_{i=1}^{n}$ as follows

Step 4.1. Let $i=1$ and execute Step 4.2 until $i>n$. If $i=n$, then let $\mathbf{y}_{1}=\mathbf{x}_{k+1}+\hat{\lambda} \mathbf{d}$, let $j=$ 1 , replace $k$ by $k+1$, and repeat Step 3 .

Step 4.2. If $d_{i}=0$, then $u_{i}=-M$ and $v_{i}=M$. If $d_{i}>0$, then $u_{i}=\left(a_{i}-y_{i}\right) / d_{i}$ and $v_{i}=$ $\left(b_{i}-y_{i}\right) / d_{i}$. If $d_{i}<0$, then $u_{i}=\left(b_{i}-y_{i}\right) / d_{i}$ and $v_{i}=\left(a_{i}-y_{i}\right) / d_{i}$. Replace $i$ by $i+1$, and repeat Step 4.2.

Step 5. Follow Step 5 from Solution I

\subsection{Solution III: Rosenbrock's method using line search (RL-method)}

Steps 1 and 2. Follow Steps 1 and 2 from Solution I. 
Step 3. Is the same as Step 3 from Solution I, except that for $k>1$, the optimal solution $\lambda_{j}$ to the problem to maximize $f\left(\mathbf{y}_{j}+\lambda \mathbf{d}_{j}\right)$ is subject to $\min \left[u_{i}\right]_{i=1}^{n} \leq \lambda \leq \max \left[v_{i}\right]_{i=1}^{n}$ as in Step 4.1 and step 4.2 from Solution II.

Step 4. Let $\mathbf{d}_{1}, \ldots, \mathbf{d}_{\mathrm{n}}$ be a new set of linearly independent orthogonal search directions by the GramSchmidt procedure. Let $\mathbf{y}_{1}=\mathbf{x}_{k+1}$, let $j=1$, replace $k$ by $k+1$, and repeat Step 3 .

Step 5. Follow Step 5 from Solution I.

\subsection{Solution IV: Rosenbrock's method using discrete steps (RD-method)}

Step 1. Select an expansion factor, $\alpha>1$, and a contraction factor, $\beta \in(-1,0)$. Let $\bar{\Delta}_{1}, \ldots, \bar{\Delta}_{n}>0$ be the initial step sizes along the coordinate directions, let $\Delta_{j}=\bar{\Delta}_{j}$ for each $(j=1, \ldots, n)$, and do the same as Step 1 from Solution I.

Step 2. Follow Step 2 from Solution I.

Step 3. If $f\left(\mathbf{y}_{j}+\Delta_{j} \mathbf{d}_{j}\right)>f\left(\mathbf{y}_{j}\right)$ and $a_{i} \leq \mathbf{y}_{i}+\Delta_{j} \mathbf{d}_{i} \leq b_{i}$, then for each $i=1, \ldots, n$, let $\mathbf{y}_{j+1}=\mathbf{y}_{j}+$ $\Delta_{j} \mathbf{d}_{j}$, and replace $\Delta_{j}$ by $\alpha \Delta_{j}$. On the contrary, let $\mathbf{y}_{j+1}=\mathbf{y}_{j}$, and replace $\Delta_{j}$ by $\beta \Delta_{j}$. If $j<n$, then replace $j$ by $j+1$, and repeat Step 3. Otherwise, if $j=n$, then go to Step 4.

Step 4. Set test $=$ "true". If $f\left(\mathbf{y}_{n+1}\right)>f\left(\mathbf{y}_{1}\right)$ and $a_{i} \leq \mathbf{y}_{n+1} \leq b_{i}$, then for each $i=1, \ldots, n$, set test $=$ "true", let $\mathbf{y}_{1}=\mathbf{y}_{n+1}$, let $j=1$, and repeat Step 3. If test $=$ "true", then go to Step 5 if $f\left(\mathbf{y}_{n+1}\right)>$ $f\left(\mathbf{x}_{k}\right)$. If test remains unchanged ("false") and $\left|\Delta_{j}\right| \leq \varepsilon$, then let $\mathbf{x}=\mathbf{x}_{k}$ and go to Step 6. Otherwise, let $\mathbf{y}_{1}=\mathbf{y}_{n+1}$, let $j=1$, and go to Step 3 .

Step 5. Let $\mathbf{x}_{k+1}=\mathbf{y}_{n+1}$. If $\left\|\mathbf{x}_{k+1}-\mathbf{x}_{k}\right\|<\varepsilon$, then let $=\mathbf{x}_{k+1}$, and go to Step 6. Otherwise, compute $\lambda_{1}, \ldots, \lambda_{n}$ from the relationship $\mathbf{x}_{k+1}-\mathbf{x}_{k}=\sum_{j=1}^{n} \lambda_{j} \mathbf{d}_{j}$, form a new set of search directions by the GramSchmidt procedure and denote these directions by $\mathbf{d}_{1}, \ldots, \mathbf{d}_{n}$, let $\Delta_{j}=\bar{\Delta}_{j}$ for each $j=1, \ldots, n$, let $\mathbf{y}_{1}=$ $\mathbf{x}_{k+1}$, replace $k$ by $k+1$, let $j=1$, and repeat Step 3 .

Step 6. Let best $t_{m}=f(\mathbf{x})$ and Sol $_{m}=\mathbf{x}$. If best $<$ best $_{m}$, then replace best by best $t_{m}$ and bestSol by Sol $_{m}$. Replace $m$ by $m+1$, and go to Step 2 .

\subsection{Solution V: Hooke and Jeeves's method using discrete steps (HD-method)}

Step 1. Choose an initial step size, $\Delta>\varepsilon$, let $\alpha>0$ be a selected acceleration factor, and do the same as Step 1 from Solution I.

Step 2. Follow Step 2 from Solution I.

Step 3. Let $=$ "true". If $f\left(\mathbf{y}_{j}+\Delta \mathbf{d}_{j}\right)>f\left(\mathbf{y}_{j}\right)$ and $a_{i} \leq \mathbf{y}_{i}+\Delta \mathbf{d}_{i} \leq b_{i}$, then for each $i=1, \ldots, n$, let test $=$ "true", let $\mathbf{y}_{j+1}=\mathbf{y}_{j}+\Delta \mathbf{d}_{j}$, and go to Step 4. On the contrary, let $\mathbf{y}_{j+1}=\mathbf{y}_{j}-\Delta \mathbf{d}_{j}$, let test $=$ "true", and go to Step 4 if $f\left(\mathbf{y}_{j}-\Delta \mathbf{d}_{j}\right)>f\left(\mathbf{y}_{j}\right)$ and $a_{i} \leq \mathbf{y}_{i}-\Delta \mathbf{d}_{i} \leq b_{i}$, for all $i=1, \ldots, n$. If test remains unchanged ("false"), then let $\mathbf{y}_{j+1}=\mathbf{y}_{j}$, and go to Step 4 .

Step 4. If $j<n$, then replace $j$ by $j+1$, and repeat Step 3. Otherwise, if $j=n$, then go to Step 5 if $f\left(\mathbf{y}_{n+1}\right)>f\left(\mathbf{x}_{k}\right)$, and go to Step 6 if $f\left(\mathbf{y}_{n+1}\right) \leq f\left(\mathbf{x}_{k}\right)$.

Step 5. Let $\mathbf{x}_{k+1}=\mathbf{y}_{n+1}$, and let $\mathbf{y}_{1}=\mathbf{x}_{k+1}+\alpha\left(\mathbf{x}_{k+1}-\mathbf{x}_{k}\right)$. Replace $k$ by $k+1$, let $j=1$, and go to Step 3. 
Step 6. If $\Delta \leq \varepsilon$, then go to Step 7. Otherwise, replace $\Delta$ by $\Delta / 2$. Let $\mathbf{y}_{1}=\mathbf{x}_{k+1}=\mathbf{x}_{k}$, replace $k$ by $k+1$, let $j=1$, and repeat Step 3 .

Step 7. Let best $t_{m}=f\left(\mathbf{x}_{k}\right)$ and Sol $_{m}=\mathbf{x}_{k}$. If best $<$ best $_{m}$, then replace best by best ${ }_{m}$ and bestSol by $S_{o l}$. Replace $m$ by $m+1$, and go to Step 2 .

Note that algorithms I, II, and III require using a procedure for minimizing or maximizing the functions of one variable without using derivatives. We use the Fibonacci search method that fits well for convex functions as well as for strictly quasiconvex functions. We do not provide an analytical proof for using the first three algorithms with a Fibonacci search indiscriminately, but a quick verification of the concavity of the function can be accomplished graphically regarding each decision variable with the others held constant, as shown in Fig. 2. Algorithms IV and V do not employ any line search; instead, they take discrete steps along the search directions involving functional evaluations, which tends to be useful when functions have several local minima, local maxima, or even saddle points.

Notably, the performance of all of the above solution procedures can be improved by choosing a good starting solution with reasonable limits. Since price-discounts should contribute to a consumption increase of the on-hand inventory and because long periods of inventory shortage are undesirable, the length of the inventory cycle must always be shorter in the models with discounts than in the models that do not allow any price-discount. Moreover, the time at which the stocks reach zero must always be near to the time at which the orders are received. Thus, the search process is simplified when using the solution of the $Z_{3}, Z_{5}, Z_{7}$ models as a lower boundary of the $Z_{1}, Z_{2}, Z_{4}$, and $Z_{6}$ models. In other words the search is simplified when optimizing $T_{1}$ and $m$ with $r_{1}=r_{2}=t_{1}=0, r_{2}=0$, or $r_{1}=t_{1}=0$, as applicable, and then using the resultant $m$ as the lower bound $\operatorname{mMin}$, and $H / m_{i}\left(\min \leq m_{i} \leq\lfloor H / \tau\rfloor\right)$ as the initial point $T_{1}\left(\tau\right.$ instead of $H / m_{i}$ for model $\left.Z_{5}\right)$.
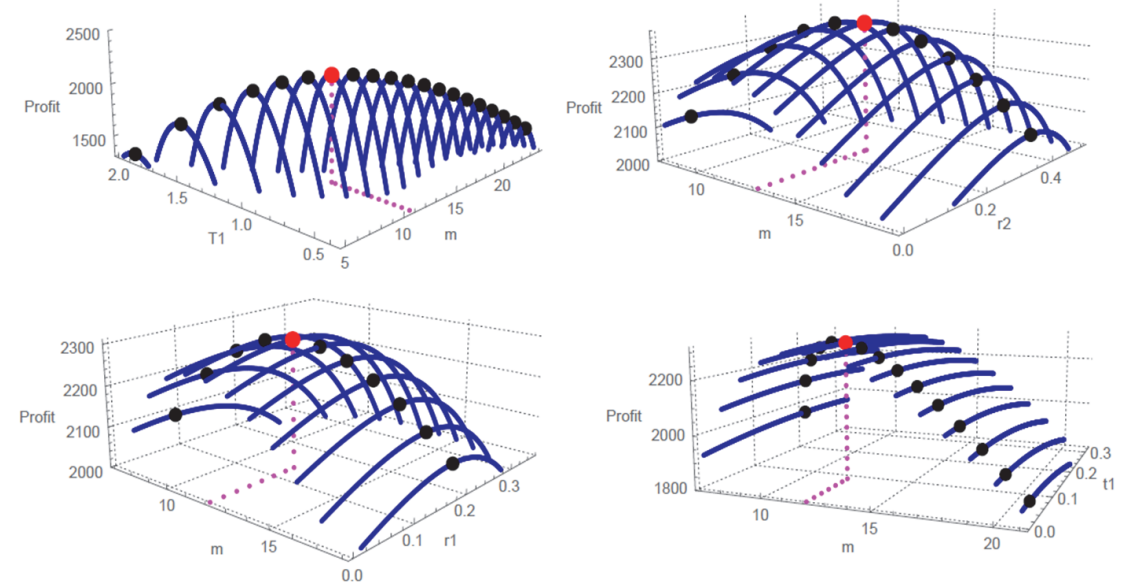

Fig. 2 Concavity of the function $Z_{1}$ regarding each continuous decision variable with the others held constant

\section{Numerical examples and analysis}

To illustrate our proposed models, we consider two numerical examples. The first example is used to compare the five different search methods, to conduct a sensitivity analysis, and to show some interesting relationships between the models. The second example is used to compare our models with scenarios neglecting TVM and shortages. For this purpose, the algorithms were coded using Wolfram Mathematica 10.3 on a $3.40 \mathrm{GHz}$ Intel Core i5 with $2 \mathrm{~GB}$ of memory RAM computer.

Example 1. The values of the following parameters are to be taken in appropriate units: $a=90.0, b=$ $0.90, s=12.0, c=5.10 ; h=0.50, \tau=0.32 ; n_{1}=n_{2}=1.91, d=0.30, C_{0}=180.0, \theta=0.15$, 
$r=0.14, l=14, p=200, \beta=0.50, H=10$. Table 1 summarizes the numerical results for the formulated models $\left(Z_{1}\right.$ to $Z_{7}$ ), and Tables 2 and 3 report the performance of the algorithms described in section 5 .

Table 1

Optimal decision variable values for models $Z_{1}$ to $Z_{7}$ (Example 1).

\begin{tabular}{rccccccc}
\hline Model & DTP & $r_{1}$ & $r_{2}$ & $t_{1}$ & $T_{1}$ & $T_{B}=H / m$ & $Q$ \\
\hline$Z_{1}$ & 2464.02 & 0.2187 & 0.2694 & 0.1306 & 0.7680 & 0.7692 & 182.2581 \\
$Z_{2}$ & 2381.99 & - & 0.2567 & - & 0.7665 & 0.7692 & 148.0724 \\
$Z_{3}$ & 2277.20 & - & - & - & 0.8956 & 0.9091 & 119.3610 \\
$Z_{4}$ & 1435.88 & - & 0.1799 & - & 0.6256 & 0.6667 & 95.7798 \\
$Z_{5}$ & 1292.60 & - & - & - & 0.7825 & 0.8333 & 83.0312 \\
$Z_{6}$ & 1202.45 & 0.2733 & - & 0.1053 & 0.3226 & 0.3846 & 65.0030 \\
$Z_{7}$ & 1019.02 & - & - & - & 0.3226 & 0.3846 & 37.8110 \\
\hline
\end{tabular}

Table 2

Algorithm results using $r_{1}=r_{2}=t_{1}=0$ and $T_{1}=\tau$ as starting points.

\begin{tabular}{|c|c|c|c|c|c|}
\hline \multirow{2}{*}{ Models } & \multicolumn{5}{|c|}{$($ Seconds elapsed, percentage change*) } \\
\hline & HD & HL & $\mathrm{RD}$ & $\mathrm{RL}$ & C \\
\hline$Z_{1}$ & $\{3.39,-\}$ & $\{59.764,8.26 \mathrm{E}-11\}$ & $\{10.901,0\}$ & $\{993.001,8.23 \mathrm{E}-11\}$ & $\{104.221,8.09 \mathrm{E}-11\}$ \\
\hline$Z_{2}$ & $\{1.13,-\}$ & $\{12.776,8.99 \mathrm{E}-11\}$ & $\{4.117,0\}$ & $\{19.532,8.99 \mathrm{E}-11\}$ & $\{9.326,8.99 \mathrm{E}-11\}$ \\
\hline$Z_{3}$ & $\{0.36,-\}$ & $\{4.072,-3.27 \mathrm{E}-11\}$ & $\{2.818,0\}$ & $\{2.723,-3.27 \mathrm{E}-11\}$ & $\{2.682,-3.27 \mathrm{E}-11\}$ \\
\hline$Z_{4}$ & $\{0.97,-\}$ & $\{16.044,-3.27 \mathrm{E}-10\}$ & $\{4.267,0\}$ & $\{19.498,-3.25 \mathrm{E}-10\}$ & $\{10.511,-3.27 \mathrm{E}-10\}$ \\
\hline$Z_{5}$ & $\{0.4,-\}$ & $\{3.234,1.66 \mathrm{E}-10\}$ & $\{2.382,0\}$ & $\{2.472,1.64 \mathrm{E}-10\}$ & $\{2.107,1.66 \mathrm{E}-10\}$ \\
\hline$Z_{6}$ & $\{3.91,-\}$ & $\{79.09,-4.72 \mathrm{E}-6\}$ & $\{10.65,-4.05 \mathrm{E}-6\}$ & $\{237.018,2.08 \mathrm{E}-7\}$ & $\{143.655,-4.72 \mathrm{E}-6\}$ \\
\hline$Z_{7}$ & $\{0.51,-\}$ & $\{7.037,-4.42 \mathrm{E}-6\}$ & $\{3.996,-1.33 \mathrm{E}-5\}$ & $\{4.88,-4.42 \mathrm{E}-6\}$ & $\{4.831,-4.42 \mathrm{E}-6\}$ \\
\hline
\end{tabular}

*Percentage changes by taking the optimal DTP's in Table 1 as reference values.

Table 3

Algorithm results using the recommended starting points.

\begin{tabular}{cccccc}
\hline \multirow{2}{*}{ Models } & \multicolumn{5}{c}{ (Seconds elapsed, percentage change*) } \\
\cline { 2 - 5 } & HD & HL & RD & RL & C \\
\hline$Z_{1}$ & $\{2.36,-\}$ & $\{2.376,-8.31 \mathrm{E}-11\}$ & $\{2.376,0\}$ & $\{2.386,0\}$ & $\{2.376,0\}$ \\
$Z_{2}$ & $\{0.53,-\}$ & $\{0.526,-9.22 \mathrm{E}-11\}$ & $\{0.526,0\}$ & $\{0.526,0\}$ & $\{0.526,0\}$ \\
$Z_{3}$ & $\{0.31,-\}$ & $\{0.303,3.09 \mathrm{E}-11\}$ & $\{0.293,0\}$ & $\{0.303,0\}$ & $\{0.293,0\}$ \\
$Z_{4}$ & $\{0.61,-\}$ & $\{0.607,3.24 \mathrm{E}-10\}$ & $\{0.607,0\}$ & $\{0.619,0\}$ & $\{0.617,0\}$ \\
$Z_{5}$ & $\{0.37,-\}$ & $\{0.384,-1.68 \mathrm{E}-10\}$ & $\{0.374,0\}$ & $\{0.384,0\}$ & $\{0.384,0\}$ \\
$Z_{6}$ & $\{1.69,-\}$ & $\{1.711,-1.35 \mathrm{E}-10\}$ & $\{1.709,0\}$ & $\{1.739,0\}$ & $\{1.719,0\}$ \\
$Z_{7}$ & $\{0.37,-\}$ & $\{0.374,3.06 \mathrm{E}-10\}$ & $\{0.384,0\}$ & $\{0.384,0\}$ & $\{0.374,0\}$ \\
\hline
\end{tabular}

*Percentage changes by taking the optimal DTP's in Table 1 as reference values.

As expected, Table 1 shows that the best profit is obtained from the $Z_{1}$ model. If the opportunity of boosting the demand through both type of discounts is missed, then the profit may drop $8 \%$ when using $Z_{3}$ instead of $Z_{1}, 48 \%$ when assuming an instant deterioration rate (model $Z_{5}$ ), and $59 \%$ when assuming a fixed life time (model $Z_{7}$ ). Comparing Table 2 and Table 3 reveals that, despite the time consumed to find a solution, all of the five algorithms found the same global maximum. The most interesting aspects revealed in these tables is the faster convergence of the HD and RD methods when compared with the HL, RL, and C methods, and the improved performance of all of the algorithms in Table 3 over Table 2 using the recommended starting solution. Regardless of the starting values, the HD algorithm consistently out-performs the other proposed algorithms. Notably, the more that the price-discount dependency of demand is captured through the models, the more economic benefits are achieved. To give a better insight of these potential benefits, Fig. 3 outlines the main relationships that can be obtained to the known pricediscount interval in which one model becomes more profitable than its immediate counterpart. By comparing models $Z_{2}, Z_{3}, Z_{5}, Z_{7}$ with models $Z_{1}, Z_{2}, Z_{4}$, and $Z_{6}$, respectively, we observe that there exists a price-discount interval in which the best DTP of the former models are always lower than any DTP provided for the latter models, whenever the corresponding additional price-discount falls within that specific interval. These intervals are given as follows 
- $Z_{1}\left(r_{1}, 0.2694,0.1306,0.7680,13\right)>Z_{2}(0.2567,0.7665,13)$ for all $r_{1}$ between $0.115 \%$ and $35.219 \%$ exclusively.

- $Z_{2}\left(r_{2}, 0.7665,13\right)>Z_{3}(0.8956,11)$ for all $r_{2}$ between $3.46 \%$ and $39.734 \%$ exclusively.

- $Z_{4}\left(r_{2}, 0.6256,15\right)>Z_{5}(0.7825,12)$ for all $r_{2}$ between $3.751 \%$ and $27.868 \%$ exclusively.

- $Z_{6}\left(r_{1}, 0.1053,0.3226,26\right)>Z_{7}(0.3226,26)$ for all $r_{1}$ between $0 \%$ and $41.792 \%$ exclusively.
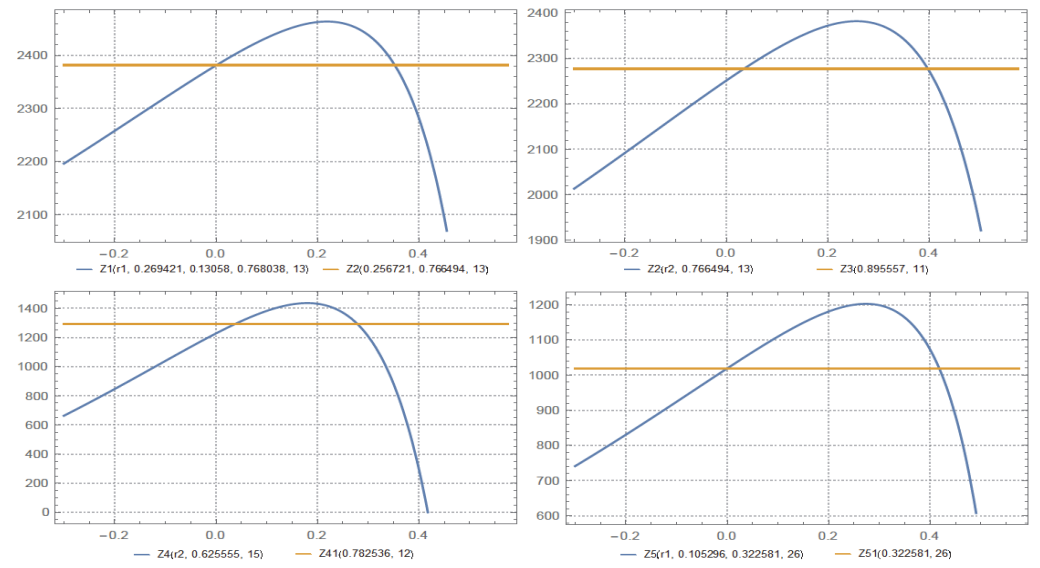

Fig. 3. The relationship between the models

We now study the effects of variations in the parameters on the model outputs. We perform a sensitivity analysis on a model with both types of discounts $\left(Z_{1}\right)$ by measuring the percentage of change in $N P V, r_{1}, r_{2}, t_{1}, B, T_{B}$, and $Q$ when one model parameter at a time is modified to $-20 \%,-10 \%,+10 \%$, and $+20 \%$ of its original value. Table 4 shows the results of this analysis, and the following conclusion can be drawn from there:

- The DTP provided for the model is more sensitive to the demand rate $a$, the selling price $s$, and the unit cost $c$, compared with the other parameters. When all of the parameters are simultaneously overestimated, the DTP is much more sensitive compared with the DTP when all of the parameters are simultaneously underestimated.

- The pre-deterioration discount is more sensitive to the stock dependent $b$, the selling price $s$, the unit cost $c$, and the effect of the pre-deterioration discount controlled by $n_{1}$, compared with the other parameters.

- The post-deterioration discount is more sensitive to the stock dependent $b$, the selling price $s$, the unit $\operatorname{cost} c$, the time at which deterioration starts $\tau$, and the effect of the post-deterioration discount controlled by $n_{2}$, compared with the other parameters.

- The time from which the pre-deterioration discount starts $t_{1}$ is more sensitive to the selling price $s$, the unit cost $c$, and the effect of the pre-deterioration discount controlled by $n_{1}$, compared with the other parameters.

- The inventory cycle $T_{B}$ and the duration of the backorder $B$ are more sensitive to the planning horizon $H$, compared with the other decision variables.

- The order quantity is more sensitive to the stock dependent $b$, the selling price $s$, the unit cost $c$, the time at which deterioration starts $\tau$, the effect of the pre-and post-deterioration discount controlled by $n_{1}$ and $n_{2}$, respectively, and the discount rate $r$, compared with the other parameters.

- The DTP, as well as the decision variables, shows a low sensitivity to underestimations and overestimations in the lost sales $\operatorname{cost} l$, the backorder $\operatorname{cost} p$, the deterioration rate $\theta$, the simulation coefficient $\beta$, the ordering $\operatorname{cost} C_{0}$, and the holding $\cos t h$. This indicates that the cost penalty is low for errors in the estimation of these parameters and correspondingly, managers should estimate these parameters reasonably instead of attempting to calculate them accurately. 
Table 4

Sensitivity analysis of the model with pre- and post-deterioration discount

\begin{tabular}{|c|c|c|c|c|c|c|c|c|}
\hline Parameter & \% Change $(\Delta P)$ & $\Delta \mathrm{NPV} / \Delta \mathrm{P}$ & $\Delta r_{l} / \Delta P$ & $\Delta r_{2} / \Delta P$ & $\Delta t_{l} / \Delta P$ & $\Delta B / \Delta P$ & $\Delta T_{B} / \Delta P$ & $\Delta Q / \Delta P$ \\
\hline \multirow[t]{4}{*}{ 20. } & -20 & 1.5827 & 0.4879 & 1.1327 & -0.5075 & -0.9091 & -0.4101 & -0.3764 \\
\hline & -10 & 1.5950 & 0.4463 & 1.0273 & -0.4526 & -0.8333 & -0.3819 & -0.4145 \\
\hline & +10 & 1.6217 & 0.0000 & 0.0000 & 0.0000 & 0.0000 & 0.0000 & 0.0000 \\
\hline & +20 & 1.6345 & 0.1907 & 0.4331 & -0.1857 & -0.3571 & -0.1680 & -0.2343 \\
\hline \multirow{4}{*}{$b$} & -20 & 0.5164 & 1.6321 & 2.3887 & 0.0164 & -0.4167 & -0.4474 & 1.0122 \\
\hline & -10 & 0.5612 & 1.4607 & 1.9329 & 0.3613 & 0.0000 & -0.2993 & 1.3434 \\
\hline & +10 & 0.6610 & 1.5350 & 2.0421 & 0.3749 & 0.0000 & -0.3553 & 1.8096 \\
\hline & +20 & 0.7285 & 1.5779 & 2.1061 & 0.3869 & 0.0000 & -0.3931 & 2.1766 \\
\hline \multirow{4}{*}{$s$} & -20 & 3.3927 & -6.8063 & 5.0000 & -7.6581 & -0.9091 & 0.2916 & 0.6603 \\
\hline & -10 & 3.6499 & 6.4192 & 9.7987 & -8.5081 & -1.8182 & -0.1340 & 3.7592 \\
\hline & +10 & 4.8893 & 5.0578 & 7.3101 & -3.8311 & -0.7143 & -0.5695 & 9.2713 \\
\hline & +20 & 6.0311 & 4.8469 & 7.0270 & -2.7131 & -0.6667 & -1.3344 & 19.0277 \\
\hline \multirow{4}{*}{$c$} & -20 & -4.9059 & -5.8671 & -8.4185 & 2.9698 & 0.9375 & 2.8469 & -35.1926 \\
\hline & -10 & -3.1142 & -5.4019 & -7.7133 & 4.1898 & 0.7143 & 1.4423 & -10.7895 \\
\hline & +10 & -1.9786 & -5.1914 & -7.3939 & 6.6347 & 0.8333 & 0.7790 & -3.7031 \\
\hline & +20 & -1.7554 & -4.9334 & -5.0000 & 7.5205 & 0.4167 & 0.5139 & -2.4949 \\
\hline \multirow{4}{*}{$h$} & -20 & -0.0719 & -0.1341 & -0.2477 & -0.0273 & 0.0000 & 0.0558 & -0.1801 \\
\hline & -10 & -0.0713 & -0.1340 & -0.2476 & -0.0273 & 0.0000 & 0.0553 & -0.1774 \\
\hline & +10 & -0.0702 & -0.1337 & -0.2473 & -0.0273 & 0.0000 & 0.0542 & -0.1720 \\
\hline & +20 & -0.0697 & -0.1336 & -0.2471 & -0.0273 & 0.0000 & 0.0536 & -0.1695 \\
\hline \multirow{4}{*}{$\tau$} & -20 & 0.4428 & 1.1358 & 1.7450 & 1.2428 & 0.0000 & -0.2954 & 0.9483 \\
\hline & -10 & 0.4536 & 1.1617 & 1.7771 & 1.2759 & 0.0000 & -0.3149 & 1.0408 \\
\hline & +10 & 0.4797 & 1.2197 & 1.8506 & 1.3507 & 0.0000 & -0.3643 & 1.2933 \\
\hline & +20 & 0.4958 & 1.2525 & 1.8930 & 1.3934 & 0.0000 & -0.3963 & 1.4715 \\
\hline \multirow{4}{*}{$n_{1}$} & -20 & 0.1102 & 4.7769 & 0.6872 & -7.4168 & -0.4167 & -0.2169 & 1.3847 \\
\hline & -10 & 0.1880 & 3.8025 & 1.3183 & -6.9956 & -0.8333 & -0.4255 & 1.6192 \\
\hline & +10 & 0.4393 & 2.5910 & 1.6152 & -5.6572 & -0.7143 & -0.4702 & 2.5339 \\
\hline & +20 & 0.6527 & 2.3009 & 1.8582 & -5.0000 & -0.6667 & -0.5269 & 3.1074 \\
\hline \multirow{4}{*}{$n_{2}$} & -20 & 0.1826 & 0.2231 & 5.0000 & -0.2263 & -0.4167 & -0.2181 & 1.2621 \\
\hline & -10 & 0.3032 & 0.4463 & 5.4307 & -0.4526 & -0.8333 & -0.4656 & 1.3314 \\
\hline & +10 & 0.5129 & 0.0000 & 2.7749 & 0.0000 & 0.0000 & -0.2628 & 1.5422 \\
\hline & +20 & 0.6022 & 0.0000 & 2.3620 & 0.0000 & 0.0000 & -0.3153 & 1.5029 \\
\hline \multirow{4}{*}{$d$} & -20 & -0.0016 & 0.0000 & -0.0069 & 0.0000 & 0.0000 & 0.0024 & -0.0035 \\
\hline & -10 & -0.0016 & 0.0000 & -0.0069 & 0.0000 & 0.0000 & 0.0024 & -0.0035 \\
\hline & +10 & -0.0016 & 0.0000 & -0.0069 & 0.0000 & 0.0000 & 0.0024 & -0.0035 \\
\hline & +20 & -0.0016 & 0.0000 & -0.0069 & 0.0000 & 0.0000 & 0.0024 & -0.0035 \\
\hline \multirow{4}{*}{$\mathrm{C} 0$} & -20 & -0.6396 & -0.1907 & -0.4331 & 0.1857 & 0.3571 & 0.1680 & 0.2343 \\
\hline & -10 & -0.6217 & 0.0000 & 0.0000 & 0.0000 & 0.0000 & 0.0000 & 0.0000 \\
\hline & +10 & -0.5969 & -0.4463 & -1.0273 & 0.4526 & 0.8333 & 0.3819 & 0.4145 \\
\hline & +20 & -0.5874 & -0.2231 & -0.5137 & 0.2263 & 0.4167 & 0.1909 & 0.2073 \\
\hline & -20 & -0.0221 & 0.0000 & -0.0935 & 0.0000 & 0.0000 & 0.0337 & -0.0480 \\
\hline${ }^{2}$ & -10 & -0.0221 & 0.0000 & -0.0936 & 0.0000 & 0.0000 & 0.0337 & -0.0478 \\
\hline$\theta$ & +10 & -0.0220 & 0.0000 & -0.0938 & 0.0000 & 0.0000 & 0.0335 & -0.0474 \\
\hline & +20 & -0.0220 & 0.0000 & -0.0940 & 0.0000 & 0.0000 & 0.0335 & -0.0472 \\
\hline & -20 & -1.2050 & -0.5275 & -0.5767 & 0.2985 & -0.4167 & 0.1760 & -1.3681 \\
\hline & -10 & -1.1202 & -0.3060 & -0.0681 & 0.1016 & -0.8333 & -0.0197 & -1.4940 \\
\hline$r$ & +10 & -0.9879 & -0.7090 & -1.0169 & 0.5313 & 0.0000 & 0.3351 & -0.8593 \\
\hline & +20 & -0.9336 & -0.7108 & -1.0216 & 0.5611 & 0.0000 & 0.3313 & -0.8091 \\
\hline & -20 & -0.0034 & 0.0000 & -0.0014 & 0.0000 & 0.0000 & -0.0332 & 0.0036 \\
\hline 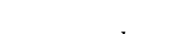 & -10 & -0.0034 & 0.0000 & -0.0014 & 0.0000 & 0.0000 & -0.0331 & 0.0036 \\
\hline$l$ & +10 & -0.0034 & 0.0000 & -0.0014 & 0.0000 & 0.0000 & -0.0329 & 0.0035 \\
\hline & +20 & -0.0034 & 0.0000 & -0.0014 & 0.0000 & 0.0000 & -0.0328 & 0.0035 \\
\hline & -20 & -0.1181 & 0.0000 & -0.0476 & 0.0000 & 0.0000 & -1.1332 & 0.1227 \\
\hline & -10 & -0.1062 & 0.0000 & -0.0428 & 0.0000 & 0.0000 & -1.0181 & 0.1099 \\
\hline$p$ & +10 & -0.0884 & 0.0000 & -0.0356 & 0.0000 & 0.0000 & -0.8461 & 0.0908 \\
\hline & +20 & -0.0815 & 0.0000 & -0.0328 & 0.0000 & 0.0000 & -0.7802 & 0.0836 \\
\hline & -20 & -0.0065 & 0.0000 & -0.0022 & 0.0000 & 0.0000 & -0.0519 & 0.0056 \\
\hline & -10 & -0.0064 & 0.0000 & -0.0022 & 0.0000 & 0.0000 & -0.0517 & 0.0056 \\
\hline$\beta$ & +10 & -0.0064 & 0.0000 & -0.0022 & 0.0000 & 0.0000 & -0.0513 & 0.0055 \\
\hline & +20 & -0.0063 & 0.0000 & -0.0021 & 0.0000 & 0.0000 & -0.0511 & 0.0055 \\
\hline & -20 & 0.5719 & 0.1070 & 0.2454 & -0.1073 & -1.5000 & -15.8058 & -0.1076 \\
\hline$H$ & -10 & 0.5397 & 0.3407 & 0.7829 & -0.3437 & -1.8182 & -14.5775 & -0.3281 \\
\hline$H$ & +10 & 0.4649 & -0.1146 & -0.2624 & 0.1144 & -0.7143 & -11.1247 & 0.1192 \\
\hline & +20 & 0.4323 & -0.1070 & -0.2454 & 0.1073 & -0.6667 & -10.3833 & 0.1076 \\
\hline & -20 & 3.0876 & -2.4845 & 5.0000 & -5.1265 & -3.1250 & -20.7697 & 0.5923 \\
\hline Al1 parametor & -10 & 3.6448 & 2.5633 & 9.2887 & -12.7846 & -3.0000 & -17.1126 & 3.7241 \\
\hline All parameters & +10 & 9.4017 & 3.5704 & 11.1727 & -10.0000 & -2.3529 & -13.5988 & 13.8340 \\
\hline & +20 & 20.8004 & 3.9784 & 6.6903 & -5.0000 & -1.3889 & -13.7297 & 20.5087 \\
\hline
\end{tabular}


Example 2. To study the effect of neglecting TVM and shortages, we consider the numerical example 1 adopted from Panda et al. (2009) where the parameters are given as follows: $a=80, b=0.3, s=10$, $c=4, h=0.6, \tau=1.2, n_{1}=n_{2}=2, d=2, C_{0}=100$, and $\theta=0.03$. Here, by assuming that the units of those parameters were given on a monthly basis, the following parameters are added to study the inclusion of TVM and shortages: $l=11, p=12, \beta=0.60, r=1.48 \%$ monthly nominal compounded continuously, and $H=5$ years. To solve this example, we used the HD-based algorithm presented in section 5. The optimal solution when ignoring the TVM and shortages is given in Table 5, whereas the optimal solution when considering the TVM and shortages is given in Table 6 . The optimal values reported in Table 5 correspond to those listed by Panda et al. (2009) in their Table 1, except for $t_{1}$ and $Q$. Because the other parameter together with the profit that we found is the same as that reported by them, we suppose their $t_{1}$ and $Q$ values were mistyped.

For the model with both pre- and post-deterioration discounts on selling price $\left(Z_{1}\right)$, we find a present value of $25525.39,6.4 \%$ greater than the present value obtained when neglecting TVM and shortages. i.e., when using the optimal values of Table 5 in the $Z_{1}$ model. The order quantity is $868.38,45.3 \%$ lower than that in Table 5. The cycle length is shorter by $17.13 \%$, the time at which the pre-deterioration discount should be started is $21.3 \%$ earlier, and the pre-and post-deterioration discounts on the selling price are $12.2 \%$ and $9.6 \%$ lower, respectively. These results and the comparative results for the other subcases $\left(Z_{2}\right.$ to $\left.Z_{7}\right)$ are given in Table 7 . The plus and minus signs indicate that the value from Table 6 is higher or lower than the corresponding value given in Table 5.

\section{Table 5}

Optimal values of the decision variables for the models ignoring TVM and shortages (Example 2)

\begin{tabular}{rcccccc}
\hline Models & $r_{1}$ & $r_{2}$ & $t_{1}$ & Cycle length & $Q$ & Profit/Cycle \\
\hline$Z_{1}$ & 0.389863 & 0.56429 & 0.171076 & 2.346761 & 1562.49 & 741.7741 \\
$Z_{2}$ & - & 0.451192 & - & 2.494501 & 618.0795 & 600.4079 \\
$Z_{3}$ & - & - & - & 2.780381 & 301.1357 & 524.4071 \\
$Z_{4}$ & - & 0.070149 & - & 1.637607 & 155.3047 & 369.1117 \\
$Z_{5}$ & - & - & - & 1.759003 & 144.4994 & 367.2905 \\
$Z_{6}$ & 0.389865 & - & 0.171098 & 1.2 & 376.5612 & 573.3267 \\
$Z_{7}$ & - & - & - & 1.2 & 115.5545 & 461.8484 \\
\hline
\end{tabular}

Table 6

Optimal decision for the models considering TVM and shortages (Example 2)

\begin{tabular}{rccccccc}
\hline Models & DTP & $r_{1}$ & $r_{2}$ & $t_{1}$ & $T_{1}$ & $T_{B}=H / m$ & $Q$ \\
\hline$Z_{1}$ & 25525.39 & 0.343991 & 0.511789 & 0.136497 & 1.943741 & 2.000 & 868.38 \\
$Z_{2}$ & 21585.55 & - & 0.417080 & - & 2.142857 & 2.143 & 438.27 \\
$Z_{3}$ & 19538.43 & - & - & - & 2.222232 & 2.222 & 234.59 \\
$Z_{4}$ & 14035.23 & - & 0.064201 & - & 1.383926 & 1.395 & 129.09 \\
$Z_{5}$ & 13976.21 & - & - & - & 1.488219 & 1.500 & 121.76 \\
$Z_{6}$ & 7391869.05 & 0.600000 & - & 0.452196 & 1.200000 & 1.200 & 974.48 \\
$Z_{7}$ & 17908.23 & - & - & - & 1.200000 & 1.200 & 115.55 \\
\hline
\end{tabular}

\section{Table 7}

Optimal value changes (\%) when TVM and shortages are considered (Example 2)

\begin{tabular}{rccccccc}
\hline Models & DTP & $r_{1}$ & $r_{2}$ & $t_{1}$ & $T_{1}$ & $T_{B}=H / m$ & $Q$ \\
\hline$Z_{1}$ & $6.4 \%$ & $-12.2 \%$ & $-9.6 \%$ & $-21.3 \%$ & - & $-17.5 \%$ & $-45.3 \%$ \\
$Z_{2}$ & $2.3 \%$ & - & $-8.3 \%$ & - & - & $-14.1 \%$ & $-29.7 \%$ \\
$Z_{3}$ & $1.3 \%$ & - & - & - & - & $-20.1 \%$ & $-22.1 \%$ \\
$Z_{4}$ & $0.8 \%$ & - & $-10.6 \%$ & - & - & $-14.8 \%$ & $-17.2 \%$ \\
$Z_{5}$ & $0.8 \%$ & - & - & - & - & $-16.8 \%$ & $-17.8 \%$ \\
$Z_{6}$ & $0.4 \%$ & $-9.0 \%$ & - & $-22.2 \%$ & - & $0.0 \%$ & $-11.8 \%$ \\
$Z_{7}$ & $0.0 \%$ & - & - & - & - & $0.0 \%$ & $0.0 \%$ \\
\hline
\end{tabular}

To further analyze the effect of including TVM and shortages, the optimal DTPs provided by the proposed $Z_{1}$ model are compared with those obtained when introducing, within $Z_{1}$, the optimal decision 
values provided by the model with both types of discounts but ignoring the TVM and shortages $\left(Z_{1}^{\prime}\right)$. By changing the planning period between 0.2 and 20 years, we observe from Fig. 4 that the DTP is slightly higher with the optimal values provided by model $Z_{1}$ (blue line) when the nominal interest rate compounded continuously is equal to $1.48 \%$. However, as both the nominal interest rate and the planning period increase, the difference between the DTP of model $Z_{1}$ and $Z_{1}^{\prime}$ also increases. Notably, in the long term, this difference tends to a constant value, approximately. After five years, we find that this difference is about $7.8 \%$ when the nominal interest rate compounded continuously is equal to $1.48 \%$. Similarly, when varying the discount rate to $2.0 \%, 2.4 \%$, and $2.8 \%$, this difference tends to $12.6 \%, 19.1 \%$, and $27.5 \%$, respectively.

The potential benefits noted from Fig.4 may be significant or not, depending on the minimum acceptable rate of return (MARR) of a company. Therefore, we measure the impact of these benefits by computing the corresponding internal rate of return (IRR) under different MARR and inflation rates scenarios. The results are summarized in Table 8 . Here, we observe that for scenarios with low and moderate MARRs, the difference in value between the IRRs of $Z_{1}$ and $Z^{\prime}{ }_{1}$ represent nearly the same percentage of the expected MARR, whether planning for one year or for 10 years. Moreover, in all of these casesincluding the high MARR scenarios - each of these IRR-differences represents a significant percentage $(14.1 \%-23.0 \%)$ of the corresponding MARRs. Therefore, according to our criteria, the additional effort required to include the TVM and the shortages in the model is worthwhile.
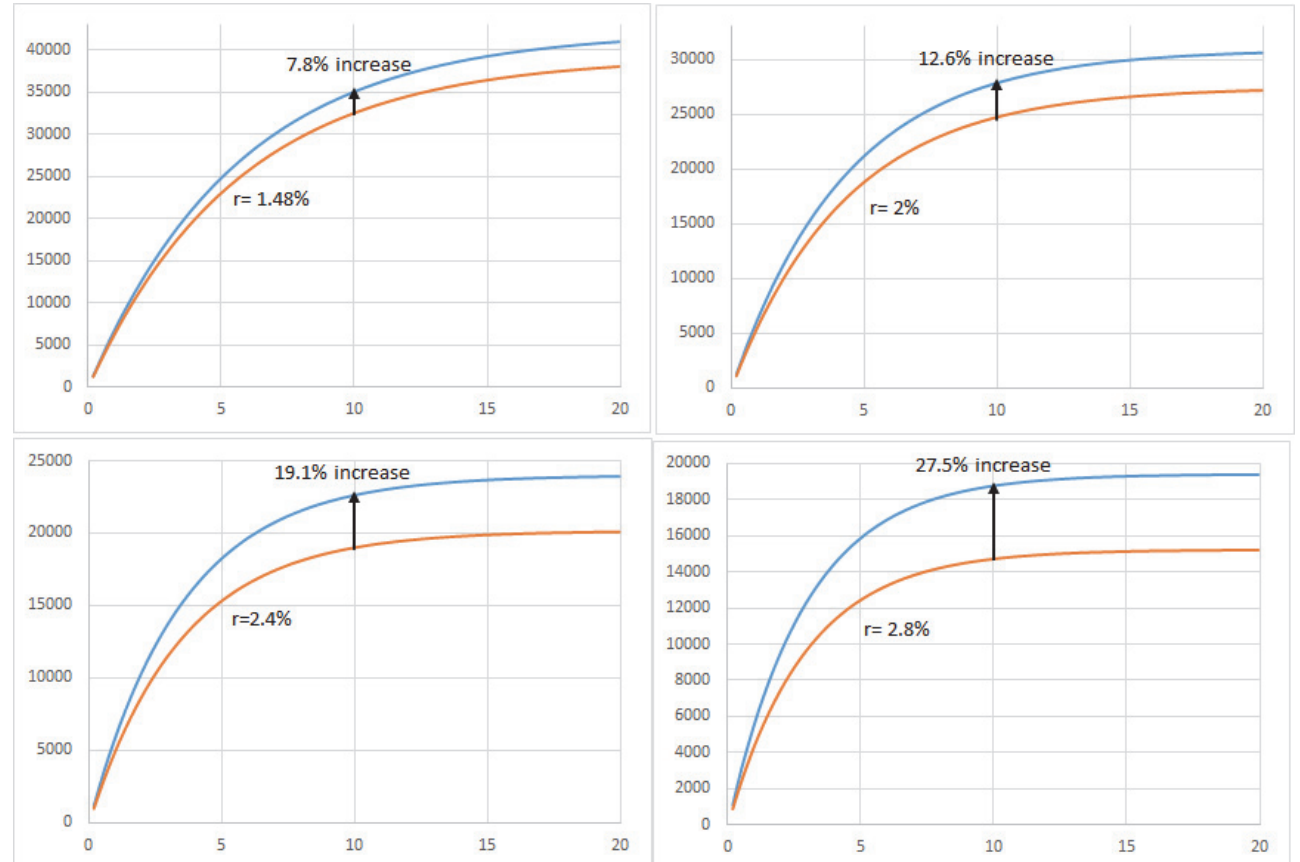

Fig. 4 DTP vs. planning horizon for model $Z_{1}$ (blue line) and model $Z_{1}^{\prime}$ (red line)

\section{Concluding remarks}

This paper has developed some practical inventory models with pre- and post-deterioration discounts on the selling price by considering the TVM and the shortages that are partially backordered depending on the waiting time. These models were developed for the grocery industry, so the mathematical models and the algorithms presented here, assist retail managers in determining a better price-discount policy when demand is affected by stock levels, markdowns, and different types of product deterioration. The models and algorithms also allow managers to analyze and identify the parameters with the potential to significantly improve the returns when they are appropriately estimated. 
Table 8

The summary of the results for different scenarios

\begin{tabular}{|c|c|c|c|c|c|c|c|c|c|c|}
\hline \multirow[t]{2}{*}{ Scenarios } & \multicolumn{2}{|c|}{ Net discount rate } & \multirow{2}{*}{$\begin{array}{l}\text { Inflation } \\
\text { (annual) }\end{array}$} & \multirow[t]{2}{*}{ MARR } & \multicolumn{2}{|c|}{ IRR with Z1 } & \multicolumn{2}{|c|}{$\begin{array}{l}\text { IRR-difference } \\
\text { respect to } Z 1^{\prime}\end{array}$} & \multicolumn{2}{|c|}{$\begin{array}{c}\text { IRR-difference/ } \\
\text { MARR }\end{array}$} \\
\hline & monthly & annual & & & 1 year & 10 years & 1 year & 10 years & 1 years & 10 years \\
\hline \multirow{4}{*}{$\begin{array}{l}\text { Low } \\
\text { MARR }\end{array}$} & \multirow{4}{*}{$1.48 \%$} & \multirow{4}{*}{$19.57 \%$} & $-0.97 \%$ & $18.60 \%$ & \multirow{4}{*}{$11.21 \%$} & \multirow{4}{*}{$11.25 \%$} & \multirow{4}{*}{$4.23 \%$} & \multirow{4}{*}{$4.27 \%$} & $22.7 \%$ & $23.0 \%$ \\
\hline & & & $1.03 \%$ & $20.60 \%$ & & & & & $20.5 \%$ & $20.7 \%$ \\
\hline & & & $4.03 \%$ & $23.60 \%$ & & & & & $17.9 \%$ & $18.1 \%$ \\
\hline & & & $6.43 \%$ & $26.00 \%$ & & & & & $16.3 \%$ & $16.4 \%$ \\
\hline \multirow{4}{*}{$\begin{array}{l}\text { Moderate } \\
\text { MARR }\end{array}$} & \multirow{4}{*}{$1.93 \%$} & \multirow{4}{*}{$26.40 \%$} & $-0.97 \%$ & $25.43 \%$ & \multirow{4}{*}{$12.06 \%$} & \multirow{4}{*}{$12.10 \%$} & \multirow{4}{*}{$5.07 \%$} & \multirow{4}{*}{$5.12 \%$} & $20.0 \%$ & $20.1 \%$ \\
\hline & & & $1.03 \%$ & $27.43 \%$ & & & & & $18.5 \%$ & $18.6 \%$ \\
\hline & & & $4.03 \%$ & $30.43 \%$ & & & & & $16.7 \%$ & $16.8 \%$ \\
\hline & & & $6.43 \%$ & $32.83 \%$ & & & & & $15.5 \%$ & $15.6 \%$ \\
\hline \multirow{4}{*}{$\begin{array}{l}\text { High } \\
\text { MARR }\end{array}$} & \multirow{4}{*}{$2.84 \%$} & \multirow{4}{*}{$41.36 \%$} & $-0.97 \%$ & $40.39 \%$ & \multirow{4}{*}{$15.37 \%$} & \multirow{4}{*}{$13.71 \%$} & \multirow{4}{*}{$8.39 \%$} & \multirow{4}{*}{$6.73 \%$} & $20.8 \%$ & $16.7 \%$ \\
\hline & & & $1.03 \%$ & $42.39 \%$ & & & & & $19.8 \%$ & $15.9 \%$ \\
\hline & & & $4.03 \%$ & $45.39 \%$ & & & & & $18.5 \%$ & $14.8 \%$ \\
\hline & & & $6.43 \%$ & $47.79 \%$ & & & & & $17.5 \%$ & $14.1 \%$ \\
\hline
\end{tabular}

When either the TVM is ignored, or the estimation of some parameters is imprecise, then we find that the resultant inventory-pricing policy is far from optimal. For example, for companies operating in countries with a high, moderate, or even a low or negative annual inflation rate, our results show how their effective yield can be significantly increased by following the pricing and inventory policy of the proposed model (see Fig. 4 and Table 8). This result is in line with many studies suggesting that the inclusion of TVM plays an important role in determining inventory policies, and should no longer be ignored. Further, even though some inventory parameters, such as shortage costs and holding costs, tend to be unknown for companies, we also find that instead of attempting to calculate those parameters with accuracy, a manager can estimate them in a reasonable way and still maintain the benefit of a profitable inventory policy (see Table 4).

Although it may be expected that the relationships shown in Fig.3 are the same when neglecting TVM and shortages, there is evidence indicating that they do not correspond. Our results suggest that there exists a lower and an upper limit for the price-discount within which the best DTP provided by the $Z_{2}$, $Z_{3}, Z_{5}$, and $Z_{7}$ models are always lower than the DTP provided by the $Z_{1}, Z_{2}, Z_{4}$, and $Z_{6}$ models. It is important to note that this finding does not correspond to those of Panda et al. (2009) for their models that neglect TVM and shortages. Instead of a lower and upper limit for the first three preceding relationships, they find that only an upper limit exists. The relationships found in our results allow managers to have flexibility when considering a two-phase price-reduction strategy for deteriorating items. Hence, future research should consider deriving the analytical expressions that contain such limits.

Although this research represents an important contribution to existing inventory models for deteriorating items with temporary price discounts, the model developed here can be further improved in several ways by including additional inventory system features. For instance, we may extend the proposed model to make it suitable for different trade credit environments (e.g., Ouyang et al., 2013; Shah \& CárdenasBarrón, 2015; Teng et al., 2016; Tiwari et al., 2016; Tyagi, 2016; Wu et al., 2016), the presence of imperfect quality (e.g., Jaggi et al., 2017) or multiple products (e.g., Rodado et al., 2017; Shavandi et al., 2012). In addition, we could generalize the model to allow for an integrated producer-buyer policy, which may include defective items and/or imperfect inspection process (e.g., Khanna et al., 2017), machine breakdown (e.g., Luong \& Karim, 2017), or the penalties and incentives provided by policymakers to incentive the reduction of greenhouse emission (e.g., Darma Wangsa, 2017). Finally, because solving the inventory problem with these and/or other features can be very complex through differential calculus; 
we could apply a simpler non-derivative approach, such as the arithmetic-geometric mean inequality (e.g., Chen et al., 2014), the cost-difference comparison (e.g., Widyadana et al., 2011) or the geometricalgebraic method (e.g., Cárdenas-Barrón, 2011).

\section{Acknowledgments}

We are grateful to the anonymous referees and the associated editor for their meticulous review and constructive comments. The first author greatly acknowledges the financial support given by Universidad de los Andes and Universidad del Atlántico.

\section{References}

Abad, P. L. (2003). Optimal pricing and lot-sizing under conditions of perishability, finite production and partial backordering and lost sale. European Journal of Operational Research, 144(0 ), 677-685.

Bakker, M., Riezebos, J., \& Teunter, R. H. (2012). Review of inventory systems with deterioration since 2001. European Journal of Operational Research, 221(2), 275-284.

Bazaraa, M. S., Sherali, H. D., \& Shetty, C. M. (2006). Unconstrained Optimization Nonlinear Programming: Theory and Algorithms (pp. 343-467): John Wiley \& Sons, Inc.

Bhunia, A. K., Shaikh, A. A., \& Gupta, R. K. (2013). A study on two-warehouse partially backlogged deteriorating inventory models under inflation via particle swarm optimisation. International Journal of Systems Science, 1-15.

Cárdenas-Barrón, L. E. (2011). The derivation of EOQ/EPQ inventory models with two backorders costs using analytic geometry and algebra. Applied Mathematical Modelling, 35(5), 2394-2407.

Chen, S.-C., Cárdenas-Barrón, L. E., \& Teng, J.-T. (2014). Retailer's economic order quantity when the supplier offers conditionally permissible delay in payments link to order quantity. International Journal of Production Economics, 155, 284-291.

Chew, E. P., Lee, C., \& Liu, R. (2009). Joint inventory allocation and pricing decisions for perishable products. International Journal of Production Economics, 120(1), 139-150.

Chew, E. P., Lee, C., Liu, R., Hong, K.-s., \& Zhang, A. (2014). Optimal dynamic pricing and ordering decisions for perishable products. International Journal of Production Economics, 157, 39-48.

Chung, C. J., \& Wee, H. M. (2008). An integrated production-inventory deteriorating model for pricing policy considering imperfect production, inspection planning and warranty-period- and stock-leveldependant demand. International Journal of Systems Science, 39(8), 823-837.

Chung, K.-J., \& Cárdenas-Barrón, L. E. (2013). The simplified solution procedure for deteriorating items under stock-dependent demand and two-level trade credit in the supply chain management. Applied Mathematical Modelling, 37(7), 4653-4660.

Chung, K.-J., Eduardo Cárdenas-Barrón, L., \& Ting, P.-S. (2014). An inventory model with noninstantaneous receipt and exponentially deteriorating items for an integrated three layer supply chain system under two levels of trade credit. International Journal of Production Economics, 155, 310317.

Darma Wangsa, I. (2017). Greenhouse gas penalty and incentive policies for a joint economic lot size model with industrial and transport emissions. International Journal of Industrial Engineering Computations, 8(4), 453-480.

Dye, C.-Y., \& Hsieh, T.-P. (2011). Deterministic ordering policy with price- and stock-dependent demand under fluctuating cost and limited capacity. Expert Systems with Applications, 38(12), 1497614983.

Dye, C.-Y., \& Hsieh, T.-P. (2013). Joint pricing and ordering policy for an advance booking system with partial order cancellations. Applied Mathematical Modelling, 37(6), 3645-3659.

Dye, C.-Y., Hsieh, T.-P., \& Ouyang, L.-Y. (2007). Determining optimal selling price and lot size with a varying rate of deterioration and exponential partial backlogging. European Journal of Operational Research, 181(2), 668-678. 
Dye, C.-Y., \& Ouyang, L.-Y. (2011). A particle swarm optimization for solving joint pricing and lotsizing problem with fluctuating demand and trade credit financing. Computers \& Industrial Engineering, 60(1), 127-137.

Dye, C.-Y., Ouyang, L.-Y., \& Hsieh, T.-P. (2007). Inventory and pricing strategies for deteriorating items with shortages: A discounted cash flow approach. Computers \& Industrial Engineering, 52(1), 29-40.

Feng, L., Chan, Y.-L., \& Cárdenas-Barrón, L. E. (2017). Pricing and lot-sizing polices for perishable goods when the demand depends on selling price, displayed stocks, and expiration date. International Journal of Production Economics, 185, 11-20.

Goyal, S. K., \& Giri, B. C. (2001). Recent trends in modeling of deteriorating inventory. European Journal of Operational Research, 134(1), 1-16.

Hou, K. L., \& Lin, L. C. (2006). An EOQ model for deteriorating items with price- and stock-dependent selling rates under inflation and time value of money. International Journal of Systems Science, 37(15), 1131-1139.

Jaggi, C. K., Cárdenas-Barrón, L. E., Tiwari, S., \& Shafi, A. (2017). Two-warehouse inventory model for deteriorating items with imperfect quality under the conditions of permissible delay in payments. Scientia Iranica, 24(1), 390-412.

Jaggi, C. K., Khanna, A., \& Nidhi, N. (2016). Effects of inflation and time value of money on an inventory system with deteriorating items and partially backlogged shortages. International Journal of Industrial Engineering Computations, 7(2), 267-282.

Jaggi, C. K., Tiwari, S., \& Goel, S. (2016). Replenishment policy for non-instantaneous deteriorating items in a two storage facilities under inflationary conditions. International Journal of Industrial Engineering Computations, 7(3), 489-506.

Janssen, L., Claus, T., \& Sauer, J. (2016). Literature review of deteriorating inventory models by key topics from 2012 to 2015. International Journal of Production Economics, 182, 86-112.

Jia, J., \& Hu, Q. (2011). Dynamic ordering and pricing for a perishable goods supply chain. Computers \& Industrial Engineering, 60(2), 302-309.

Khanna, A., Kishore, A., \& Jaggi, C. K. (2017). Strategic production modeling for defective items with imperfect inspection process, rework, and sales return under two-level trade credit. International Journal of Industrial Engineering Computations, 8(1), 85-118.

Koschat, M. A. (2008). Store inventory can affect demand: Empirical evidence from magazine retailing. Journal of Retailing, 84(2), 165-179.

Krishnan, H., \& Winter, R. A. (2010). Inventory dynamics and supply chain coordination. Management Science, 56(1), 141-147.

Li, Y., Lim, A., \& Rodrigues, B. (2008). Note--Pricing and Inventory Control for a Perishable Product. Manufacturing \& Service Operations Management, 11(3), 538-542.

Luong, H. T., \& Karim, R. (2017). An integrated production inventory model of deteriorating items subject to random machine breakdown with a stochastic repair time. International Journal of Industrial Engineering Computations, 8(2), 217-236.

Maihami, R., \& Nakhai Kamalabadi, I. (2012). Joint pricing and inventory control for non-instantaneous deteriorating items with partial backlogging and time and price dependent demand. International Journal of Production Economics, 136(1), 116-122.

Mishra, U., Cárdenas-Barrón, L., Tiwari, S., Shaikh, A., \& Treviño-Garza, G. (2017). An inventory model under price and stock dependent demand for controllable deterioration rate with shortages and preservation technology investment. Annals of Operations Research, 254(1/2), 165-190.

Ouyang, L.-Y., Yang, C.-T., Chan, Y.-L., \& Cárdenas-Barrón, L. E. (2013). A comprehensive extension of the optimal replenishment decisions under two levels of trade credit policy depending on the order quantity. Applied Mathematics and Computation, 224, 268-277.

Panda, S., Saha, S., \& Basu, M. (2009). An EOQ model for perishable products with discounted selling price and stock dependent demand. Central European Journal of Operations Research, 17(1), 31-53.

Pang, Z. (2011). Optimal dynamic pricing and inventory control with stock deterioration and partial backordering. Operations Research Letters, 39(5), 375-379. 
Pentico, D. W., \& Drake, M. J. (2011). A survey of deterministic models for the EOQ and EPQ with partial backordering. European Journal of Operational Research, 214(2), 179-198.

Rodado, D. N., Escobar, J. W., García-Cáceres, R. G., \& Atencio, F. A. N. (2017). A mathematical model for the product mixing and lot-sizing problem by considering stochastic demand. International Journal of Industrial Engineering Computations, 8(2), 237-250.

Shah, N. H., \& Cárdenas-Barrón, L. E. (2015). Retailer's decision for ordering and credit policies for deteriorating items when a supplier offers order-linked credit period or cash discount. Applied Mathematics and Computation, 259, 569-578.

Shavandi, H., Mahlooji, H., \& Nosratian, N. E. (2012). A constrained multi-product pricing and inventory control problem. Applied Soft Computing, 12(8), 2454-2461.

Soni, H. N., \& Patel, K. A. (2012). Optimal pricing and inventory policies for non-instantaneous deteriorating items with permissible delay in payment: Fuzzy expected value model. International Journal of Industrial Engineering Computations, 3(3), 281-300.

Teng, J.-T., Cárdenas-Barrón, L. E., Chang, H.-J., Wu, J., \& Hu, Y. (2016). Inventory lot-size policies for deteriorating items with expiration dates and advance payments. Applied Mathematical Modelling, 40(19), 8605-8616.

Tiwari, S., Cárdenas-Barrón, L. E., Khanna, A., \& Jaggi, C. K. (2016). Impact of trade credit and inflation on retailer's ordering policies for non-instantaneous deteriorating items in a two-warehouse environment. International Journal of Production Economics, 176, 154-169.

Tyagi, A. P. (2016). An inventory model with a new credit drift: Flexible trade credit policy. International Journal of Industrial Engineering Computations, 7(1), 67-82.

Valliathal, M., \& Uthayakumar, R. (2011). Simple approach of obtaining the optimal pricing and lotsizing policies for an EPQ model on deteriorating items with shortages under inflation and timediscounting. Istanbul University Journal Of The School Of Business Administration, 40(2), 304-320.

Wee, H.-M., \& Law, S.-T. (2001). Replenishment and pricing policy for deteriorating items taking into account the time-value of money. International Journal of Production Economics, 71(1-3), 213-220.

Widyadana, G. A., Cárdenas-Barrón, L. E., \& Wee, H. M. (2011). Economic order quantity model for deteriorating items with planned backorder level. Mathematical and Computer Modelling, 54(5), $1569-1575$

Wu, J., Al-khateeb, F. B., Teng, J.-T., \& Cárdenas-Barrón, L. E. (2016). Inventory models for deteriorating items with maximum lifetime under downstream partial trade credits to credit-risk customers by discounted cash-flow analysis. International Journal of Production Economics, 171, 105-115.

Wu, J., Ouyang, L.-Y., Cárdenas-Barrón, L. E., \& Goyal, S. K. (2014). Optimal credit period and lot size for deteriorating items with expiration dates under two-level trade credit financing. European Journal of Operational Research, 237(3), 898-908.

Yang, H.-L., \& Chang, C.-T. (2013). A two-warehouse partial backlogging inventory model for deteriorating items with permissible delay in payment under inflation. Applied Mathematical Modelling, 37(5), 2717-2726.

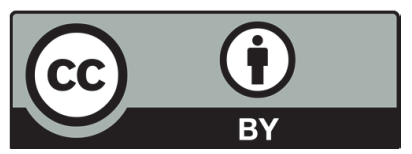

(C) 2019 by the authors; licensee Growing Science, Canada. This is an open access article distributed under the terms and conditions of the Creative Commons Attribution (CCBY) license (http://creativecommons.org/licenses/by/4.0/). 